\title{
EXPERIMENTS ON FLUIDELASTIC VIBRATIONS \\ OF TUBE ARRAYS
}

by

S. S. Chen, J. A. Jendrzejczyk, and M. W. Wambsganss

Components Technology Division

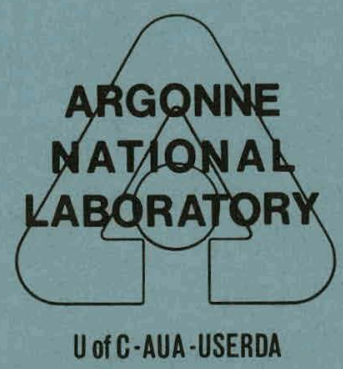

Base Technology

Apri1 1977 


\section{DISCLAIMER}

This report was prepared as an account of work sponsored by an agency of the United States Government. Neither the United States Government nor any agency Thereof, nor any of their employees, makes any warranty, express or implied, or assumes any legal liability or responsibility for the accuracy, completeness, or usefulness of any information, apparatus, product, or process disclosed, or represents that its use would not infringe privately owned rights. Reference herein to any specific commercial product, process, or service by trade name, trademark, manufacturer, or otherwise does not necessarily constitute or imply its endorsement, recommendation, or favoring by the United States Government or any agency thereof. The views and opinions of authors expressed herein do not necessarily state or reflect those of the United States Government or any agency thereof. 


\section{DISCLAIMER}

Portions of this document may be illegible in electronic image products. Images are produced from the best available original document. 
The facilities of Argonne National Laboratory are owned by the United States Government. Under the terms of a contract (W-31-109-Eng-38) between the U. S. Energy Research and Development Administration, Argonne Universities Association and The University of Chicago, the University employs the staff and operates the Laboratory in accordance with policies and programs formulated, approved and reviewed by the Association

\section{MEMBERS OF ARGONNE UNIVERSITIES ASSOCIATION}

The University of Arizona

Carnegie-Mellon University

Case Western Reserve University

The University of Chicago

University of Cincinnati

Illinois Institute of Technology

University of Illinois

Indiana University

Iowa State University

The University of Iowa
Kansas State University

The University of Kansas

Loyola University

Marquette University

Michigan State University

The University of Michigan

University of Minnesota

University of Missouri

Northwestern University

University of Notre Dame
The Ohio State University

Ohio University

The Pennsylvania State University

Purdue University

Saint Louis University

Southern Illinois University

The University of Texas at Austin

Washington University

Wayne State University

The University of Wisconsin

NOTICE

This report was prepared as an account of work sponsored by the United States Government. Neither the United States nor the United States Energy Research and Development Administration, nor any of their employees, nor any of their contractors, subcontractors, or their employees, makes any warranty, express or implied, or assumes any legal liability or responsibility for the accuracy, completeness or usefulness of any information, apparatus, product or process disclosed, or represents that its use would not infringe privately-owned rights. Mention of commercial products, their manufacturers, or their suppliers in this publication does not imply or connote approval or disapproval of the product by Argonne National Laboratory or the U. S. Energy Research and Development Administration 


\section{EXPERIMENTS ON FLUIDELASTIC VIBRATIONS \\ OF TUBE ARRAYS}

\section{by}

S. S. Chen, J. A. Jendrzejczyk, and M. W. Wambsganss

Components Technology Division
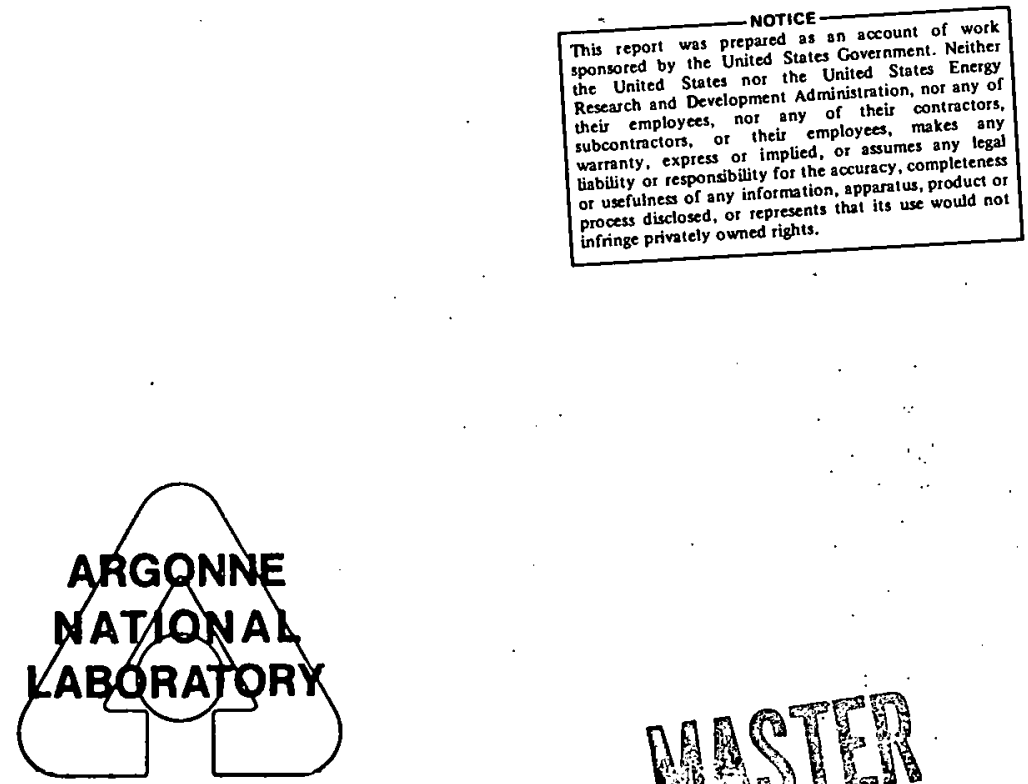

U OfC-AUA-USERDA

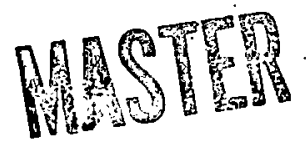

Base Technology

Apr11 1977 


\section{SUMMARY}

The work reported herein was performed as part of the base, technology activity under Flow Induced Vibration Program (189a No. CA054) sponsored by ERDA/RDD. The overall objective of the activity is to develop new and/or improved, experimentally-validated analytical methods and guidelines for designing LMFBR components to avold detrimental flow induced vibration.

Many reactor system components, such as heat exchanger tubes and reactor fuel pins are long, slender, beam-11ke components typically arranged in bundles and immersed in a flowing 1iquid. As such, they are susceptible to flow Induced vibration. Due to fluid coupling, the tubes will respond in one or several of coupled modes. Therefore, understanding the coupled modes is essential in design to avold detrimental flow-1nduced vibrations.

A general method of analysis was developed recently for predicting the natural frequencies, mode shapes, and tube responses of tube arrays In liquid; the method can be applied to tube arrays arranged in any pattern. The objective of this report is to present the results of several series of experiments designed to verify the theory.

Four series of tube arrays are tested. The arrangements of the tubes are as follows: (a) a row of five tubes with the gap to tube radius ratin $(G / R)$ equa1 to $2.0,1.0$; and 0.25 ; (b) three-tube arrays in ther staggered arrangement with $\mathrm{G} / \mathrm{R}$ equal to $2.0,1.0$ and 0.5 ; (c) seven-tube arrays in the staggered arrangement with $G / R$ equal to $1.5,1.0$ and 0.4 ; and. (d) fourtube array in a square pattern with $G / R=0.5$. The fourth series is tested under five different conditions: (1) fully submerged in unconfined water; (2) partially submerged in water; (3) near a flat wall; (4) contained in a circular cylinder; and (5) fully submerged in a liquid of high viscosity (mineral oil). A means to excite the tubes is provided by an electromagnetic exciter assembly. A servo system can be used to control 
input. Response in the form of tube acceleration is measured using two accelerometers mounted on each tube. The data is processed in a fast Fourier Transform Analyzer.

An analysis is made for each test case. In the analysis, the equations of motion and boundary conditions for each tube are derived including fluid coupling. Using the uncoupled modal function, one can reduce the partlal differential equations to a system of second order ordinary differential equations, from which coupled natural frequencies and tube responses can be calculated.

The detailed information. for uncoupled and coupled natural frequencies, mode shapes, damping, and tube response are presented in the report. The experimental data and analytical results are found to be in good agreement. Therefore, the analytical method developed earlier can be applied to different situations. The results of this investigation have applications to heat exchanger tube banks, fuel assemblies, and other structural components with multiple circular cylindrical elements. 
TABLE OF CONTENTS

SUMMARY

Page

LIST OF ILLUSTRATIONS

iv

LIST OF TABLES

vi

NOMENCLATURE

viii

I. INTRODUCTION

II. EXPERIMENTAL DESCRIPTION

III. TEST PROCEDURES

A. Air Environment 3

B. Liquid Environment 4

IV. ANALYTICAL METHOD 5

v. COMPARISON OF EXPERIMENTAL AND THEORETICAL RESULTS

A. Uncoupled Natural Frequencies 9

B. Coupled Natura1 Frequencies 9

C. Mode Shapes $\quad 10$

D: Steady-State Responses 11

E. Transient Responses $\quad 11$

VI. EFFECTS OF VARIOUS PARAMETERS ON TUBE RESPONSES 12

A. Gap-to-Radius Ratio 12

B. Flat Wall 12

C. Eccentricity of Outside Container 12

D. Water Depth 12

E. Fluid Viscosity 13

F. Uncoupled Vibration 13

VII. CONCLUSIONS 13

$\begin{array}{ll}\text { ACKNOWLEDGMENTS } & 14\end{array}$

REFERENCES $\quad 14$ 
4 Acceleration-time trace and power spectral density of tube acceleration for tube 2 in air $(G / R=0.25)$ Power spectral density of tube acceleration for a row of five tubes in air $(G / R=0.25)$ Acceleration-time trace and power spectral density of acceleration for tube 2 in water $(G / R=0.25)$ Power spectral density of tube acceleration in water $(G / R=0.25)$

Mathematical model used in analysis 


\section{LIST OF ILLUSTRATIONS (Contd.)}

No.

18 Natural frequencies as a function of the ratio of water depth to tube length $(h / l)$

Response of tube 6 in the y direction based on uncoupled and coupled vibrations for a 7 -tube array $(G / R=0.4)$

in water

Response of tube 4 in the $y$ direction based on uncoupled and coupled vibrations for the 4-tube array in 


\section{LIST OF TABLES}

No.

1

2

3

4

5

6

8

9

10

11

12
Title

Page

Experimental and analytical results for uncoupled

vibration of a row of five tubes

Experimental and analytical results for uncoupled

vibration of a group of three tubes

Experimental and analytical results for uncoupled

vibration of a group of seven tubes

Experimental and analytical results for uncoupled

vibration of the four-tube array in unconfined water

Experimental and analytical results for uncoupled

vibration of the four-tube array near a flat wall

40

Experimental and analytical results for uncoupled

vibration of the four-tube array contained in a

cylinder

Experimental and analytical results for coupled

vibration of 5 tubes

Experimental and analytical results for coupled

vibration of 3 tubes

Experimental and analytical results for coupled

vibration of 7 tubes

Experimental and analytical results for coupled

vibration of the four-tube array in unconfined water

Experimental and analytical results for coupled

vibration of the four-tube array near a flat wall

Experimental and analytical results for coupled

vibration of the four-tube array contained in a

cylinder 
Experimental and analytical results for coupled vibration of the four-tube array partially submerged in water Experimental results for uncoupled vibration of the four-tube array in viscous fluids

Experimental and analytical results for natural frequencies of coupled vibration in viscous fluids 


\section{NOMENCLATURE}

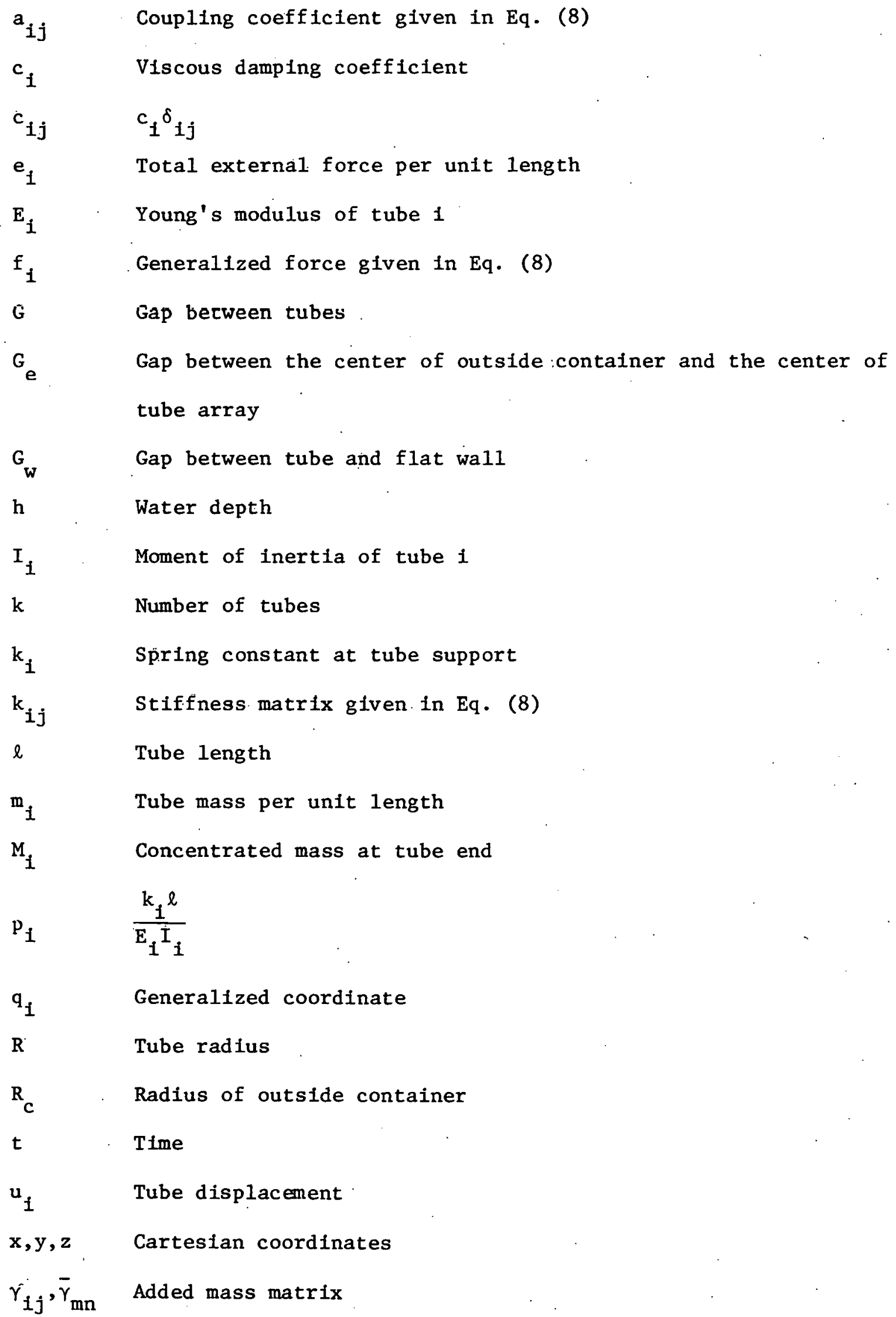


NOMENCLATURE (Contd.)

$\begin{array}{ll}\delta_{1 j} & \text { Kronecker's delta } \\ \phi_{1} & \text { Modal function of uncoupled mode for tube } 1 \\ \Omega_{1} & \text { Circular frequency of uncoupled mode of tube } 1 \\ \omega & \text { Natural frequency of coupled mode }\end{array}$




\section{INTRODUCTION}

When a tube bundle vibrates in a liquid, due to fluid coupling, the tubes will oscillate as a group with definite phase relations among the tubes; this type of oscillation is called coupled vibration. On the other hand, if only one of the tubes is oscillating while all others are held stationary, it is called uncoupled vibration. Coupled and uncoupled vibrations of tube bundles are important in many practical system components; such as heat exchanger tubes, nuclear fuel assemblies, transmission lines, piles, and other simflar components. Understanding the vibrational characteristics of tube bundles is essential in design to avoid detrimental flow-induced. vibrations.

Many investigations of tube bundles vibrating in a liquid have been made to obtain a better understanding of tube vibration phenomena; a list of those investigations can be found in Reference 1 . However, those studies are limited to some special tube arrangements. A general method of analysis was developed recently for predicting the natural frequencies, mode shapes, and tube responses of a group of tubes in a liquid [1-3]; the method can be applied to tube bundles arranged in any pattern. The objective of this report is to present the results of four eerice of experiments designed to obtain the information on coupled tube/fluid vibrations. Experimental data are found to be in good agreement with the analytical results; thus, the theory developed previousiy is sound and can be used with confidence.

\section{EXPERIMENTAL DESCRIPTION}

The test rig is shown in FIg. $1 .^{*}$ It is a tank fabricated from four luclte plates fastened to a base plate. The tank is $35.56 \mathrm{~cm}(14 \mathrm{in.})$ long, $35.56 \mathrm{~cm}$ (14 in.) wide, and $40.64 \mathrm{~cm}$ (16 in.) deep. A brass block bolted to the tank base is provided for installing the test assembly. 
Four sets of tube assembly are tested. The arrangements of the tubes are shown in Fig. 2: (1) a row of five tubes with the gap to the radius ratio $(G / R)$ equal to $2.0,1.0$, and 0.25 ; (2) a group of three tubes in the staggered arrangement with G/R equal to $2.0,1.0$, and 0.5 ; (3) a group of seven tubes in the staggered arrangement with $G / R$ equal to $1.5,1.0$, and 0.4 ; and (4) a group of four tubes arranged in a square pattern with $G / R=0.5$. The fourth series is tested under five different conditions: (a) fully submerged in unconfined water; (b) partially submerged in water; (c) near a flat wall; (d) contained in a circular cylinder; (e) fully submerged in a liquid of high viscosity (mineral oil). The tube assembly consists of a group of brass tubes with $1.27 \mathrm{~cm}(0.5 \mathrm{in.})$ outside diameter, $0.159 \mathrm{~cm}$ (1/32 in.) wall thickness, and $30.48 \mathrm{~cm}(12 \mathrm{ln.})$ long. Each tube element is soldered to a brass plate as shown in Fig. 3. The assembly is then mounted on the brass block at the center of the tank base.

A means to excite the tubes is provided by an electromagnetic exciter assembly, which is represented by the arrows in Fig. 2: This exciter assembly consists of a permanent magnet embedded in an aluminum mounting block which is screwed to the free end of a tube in the assembly, and a coil supported by a post fixed to the tank base. An alternating current applied to the coil from a signal generator induces an alternating magnetic field which, in turn, produces a force on the tube through the embedded magnet. In each assembly, only one tube is provided with the exciter assembly; those tubes with magnet are tube 5 in case 1 , tube 3 in case 2, tube 6 in case 3 and tube 4 in case 4 . A servo system can be used to control the current input or acceleration output, as desired.

Response, in the form of tube acceleration; is measured using two accelerometers mounted on each tube. The accelerometers are cemented to a small aluminum block with their sensitive axes orthogonal to each other. 
The mounting aluminum block is then.mounted țo the free end of the tube by a screw such that the sensitivity axes are parallel to the $x$ and $y$ directions. These accelerometers are provided by the manufacturer with leads attached. The wire leads from the accelerometers are passed through the tube, tube base plate, brass block, and tank base, and then attached. to a charge amplifier. A fast Fourler transform analyzer is used to process the data.

\section{TEST PROCEDURES}

\section{A. Air Environment}

Testing in air was performed to determine the natural frequency and damping for each tube and to observe the effect of coupling in air. The test for each tube assembly consists of two phases.

(1) Uncoupled Vibration - Additional supports to the free ends of the tubes are provided using wooden wedges and two posts fixed to the tank base for all tubes except the one to be tested. Those tubes with an additional support have much higher natural frequencies, and can be considered as fixed. The tube is excited by plucking it at the free end. The transient response of the tube is recorded. Then, the damping is obtained from the log decrement of the acceleration trace and the natural frequency is determined from the power spectrum of the acceleration. Each tube is tested in two orthogonal directions. Figure 4 shows a typical example of the results from the tests.

(2) Coupled Vibration - The coupling effect of the air is small. However, there is some tube interaction caused by mechanical coupling through the base end plate. After the uncoupled natural frequency and damping are found for each tube, the additional supports at the top of the tubes are removed. The tube assembly is then excited by plucking any one of the tubes. From the power spectrum of the response of any one of the 
tubes, one can identify the coupled natural frequencies in air. The coupling in air is found to be small; thus, coupled vibration test in air was made only for a few cases. Figure 5 shows a typical example of the power spectral density of tube acceleration.

\section{B. Liquid Environment}

All tests were conducted in water except the last test in the fourth sertes in mineral o11. Testing in liquid was performed to determine the uncoupled natural frequency and damping for each tube, coupled natural frequencies, mode shapes, steady-state response, and transient response. These tests consist of five phases:

(1) Uncoupled Vibration - The same procedure as in air environment was used to determine the natural frequency and damping for each tube in two orthogonal directions. In this test, all other tubes except the one being tested are jammed tight by wedges to eliminate responses of the surrounding tubes. Figure 6 shows the acceleration-time trace and power spectral density for a typical case.

(2) Coupled Natural Frequencies - Coupled natural frequencies were determined from the power spectrum of accelerometer signals in response to a plucking of the tubes. Since there are many modes in a frequency band and some of the modes are not easily excited, different methods of plucking have to be used to find all coupled modes. For example, two tubes may be plucked simultaneously. Figure 7 shows the power spectrum for tubes 4 and 5 when tubes 1 and 5 are excited at the same time. The test is repeated several times to obtain all natural frequencies of coupled modes. The coupled natural frequencies obtained from each test are then averaged.

(3) Mode Shapes - Once all coupled natural frequencies are determined from plucking tests, a sinusoidal current with its frequency equal to one 
of the coupled natural frequencies is applied to the coils. Thus, the tubes are set in resonance. After the tubes reach the steady state, the two accelerometer signals from each tube are recorded on an FM magnetic tape for all tubes simultaneously. From these steady-state accelerationtime traces, one can study the relative motions (mode shapes) of the tubes. This procedure is carried out for all coupled natural frequencies.

(4) Steady-state Responses - For each tube assembly, a sinusoidal current with a constant amplitude controlled by a servo system is applied to the coils and slowly swept through the frequency band of interest. The responses of the tubes as functions of the excitation frequency are recorded. From the response curves, coupled natural frequencies can be identified and the damping of some coupled modes can be estimated using the bandwidth method.

(5) Transient Responses - The transient responses of the tubes are also recorded for some tube assemblies. This is done by plucking one tube and recording the acceleration for each tube simultaneously.

IV. ANALYTICAL METHOD

One of the objectives of the experiments is to verify the theory developed earlier [1,3]. Therefore, analytical studies are made for each tube assembly for comparison. The mathematical model is given in Fig. 8 . The method of analysis is the same as that presented in Refs. 1 and 4 .

Tn a group of $k$ tubes, each tule can move in the $x$ and $y$ directions. Let $u_{1}\left(i=1\right.$. to $k$ ) and $u_{i}(i-k+1$ and $2 k)$ represent the displacement components of tube $i$ in the $x$ and $y$ directions respectively. The equation of motion for tube 1 is [1]

$$
E_{i} I_{i} \frac{\partial^{4} u_{i}}{\partial z^{4}}+c_{i} \frac{\partial u_{i}}{\partial t}+m_{i} \frac{\partial^{2} u_{i}}{\partial t^{2}}+\sum_{j=1}^{2 k} \gamma_{i j} \frac{\partial^{2} u_{i}}{\partial t^{2}}=e_{i} \text {, }
$$

where $t$ is time, $z$ is axial coordinate, $m_{1}$ is tube mass per unit length, 
$E_{i} I_{i}$ is flexural rigidity, $c_{i}$ is damping coefficient, $e_{i}$ is excitation force, and $\gamma_{1 j}$ is added mass matrix. For partially submerged tubes, Eq. (1) is applied to the portion submerged in liquid, while the equation of motion for the portion in air is corresponding to Eq. (1) by setting $\gamma_{1 j}=0$. Note that the variables with the index 1 (or $j$ ) from 1 to $k$ are associated with the motion in the $x$ direction while from $k+1$ to $2 k$ in the $y$ arection.

The method for calculating the added mass matrix for tube arrays In an infinite fluid and contained in a circular cylinder have been discussed previously [1,3]. For tube arrays near a flat wall, the following procedure can be employed. A group of $k$ tubes near a flat wall is mathematicaliy equivalent to the problem of $2 \mathrm{k}$ tubes which are located and move symmetrically about the flat wall as shown in Fig. 9. Therefore, if the added mass matrix for $2 k$ tubes in an infinite fluid is known, the corresponding added mass matrix for $k$ tubes near a flat wall can be calculated. Let the added mass matrix for $2 \mathrm{k}$ tubes in an infinite fluid be $\left[\bar{\gamma}_{\mathrm{mn}}\right], \mathrm{m}, \mathrm{n}=1,2,3, \ldots 4 \mathrm{k}$, and the added mass matrix for $\mathrm{k}$ tubes near a wall be $\left[\gamma_{\mathrm{mn}}\right], \mathrm{m}, \mathrm{n}=1,2,3, \ldots 2 \mathrm{k} . \gamma_{\mathrm{mn}}$ is given by

$$
\begin{aligned}
& \gamma_{\mathrm{mn}}=\bar{\gamma}_{\mathrm{mn}}+\bar{\gamma}_{\mathrm{m}, \mathrm{k}+\mathrm{m}}, \\
& \gamma_{\mathrm{m}, \mathrm{k}+\mathrm{n}}=\bar{\gamma}_{\mathrm{m}, 2 \mathrm{k+n}}-\bar{\gamma}_{\mathrm{m}, 3 \mathrm{k}+\mathrm{n}}, \\
& \gamma_{\mathrm{k}+\mathrm{m}, \mathrm{u}}=\bar{\gamma}_{2 \mathrm{k}+\mathrm{m}, \mathrm{n}}+\bar{\gamma}_{2 \mathrm{k}+\mathrm{m}, \mathrm{k}+\mathrm{n}}, \\
& \gamma_{\mathrm{k}+\mathrm{m}, \mathrm{k}+\mathrm{n}}=\bar{\gamma}_{2 \mathrm{k}+\mathrm{m}, 2 \mathrm{k}+\mathrm{n}}-\bar{\gamma}_{2 \mathrm{k}+\mathrm{m}, 3 \mathrm{k}+\mathrm{n}}, \\
& \mathrm{m,n}=1,2,3 \ldots \mathrm{k} .
\end{aligned}
$$

Each tube is elastically restrained against rotation by a torsional spring with spring constant $k_{1}$, and a concentrated mass $\dot{M}_{1}$ attached to the free end; the mass $M_{1}$ represents the masses of the accelerometers, permanent magnet, and aluminum mounting block. Therefore the boundary 
conditions are:

At zero:

$$
u_{1}=0 \text { and } E_{1} I_{1} \frac{\partial^{2} u_{1}}{\partial z^{2}}=k_{1} \frac{\partial u_{1}}{\partial z}
$$

and at $z=\ell$ :

$$
\frac{\partial^{2} u_{i}}{\partial z^{2}}=0 \text { and } E_{1} I_{i} \frac{\partial^{3} u_{i}}{\partial z^{3}}=M_{1} \frac{\partial^{2} u_{i}}{\partial t^{2}} \text {. }
$$

where, $l$ is the length of the tubes. Without loss of generality, the Initlal state of the tubes may be assumed as follows:

$$
\left.u_{1}(z, t)\right|_{t=0}=0 \quad \text { and }\left.\quad \frac{\partial u_{i}(z, t)}{\partial t}\right|_{t=0}=0 \text {. }
$$

It is assumed that only the vibrations of the mode with no nodal point along the tube axis are significant and all others are negligible. Let

$$
u_{i}(z, t)=q_{i}(t) \phi_{i}(z),
$$

where $\phi_{1}$ is the modal function for uncoupled vibration of tube 1 such that

$$
\frac{1}{\ell} \int_{0}^{\ell} \phi_{1}^{2}(z) \mathrm{d} z=1
$$

Using Eqs. (1), (3), (4), and (5) yte 1ds

$$
[\mathrm{M}]\{\ddot{\mathrm{Q}}\}+[\mathrm{C}]\{\dot{\mathrm{Q}}\}+[\mathrm{K}]\{\mathrm{Q}\}=\{\mathrm{F}\} \text {, }
$$

and

$$
\begin{aligned}
& \{Q\}_{t=0}=\{0\}, \\
& \{Q\}_{t=0}=\{0\},
\end{aligned}
$$

where $[\mathrm{M}],[\mathrm{C}]$, and $[\mathrm{K}]$ are symetric matrices with elements $m_{i j}, c_{i j}$ and $k_{i j}$, and [Q] and [F] are general coordinate and generalized force with elements $q_{1}$ and $f_{i}$, in which 


$$
\begin{aligned}
& m_{i j}=m_{i} \delta_{i j}+\gamma_{i j} a_{i j}, \\
& c_{i j}=c_{i} \delta_{i j}, \\
& k_{i j}=\left(m_{i}+\gamma_{i 1}\right) \Omega_{1}^{2} \delta_{1 j}, \\
& f_{i}=\frac{1}{\ell} \int_{0}^{l} e_{i} \phi_{i} d z, \\
& a_{i j}=\frac{1}{\ell} \int_{0}^{\ell} \phi_{i} \phi_{j} d z,
\end{aligned}
$$

and $\Omega_{i}$ is the circular frequency of the uncoupled mode of tube $i$ in water.

For free vibration, neglect damping and forcing terms and let

$$
\{Q\}=\{\bar{Q}\} \exp (j \omega t) \text {. }
$$

Natural frequencies and mode shapes of coupled tube/fluid vibration are computed from the undamped homogeneous equations

$$
[\mathrm{K}]\{\overline{\mathrm{Q}}\}=\omega^{2}[\mathrm{M}]\{\overline{\mathrm{Q}}\} \quad \text {. }
$$

Equation (10) will give $2 k$ natural frequencies for a group of $k$ tubes.

Using the normal modes, Eq. (7) can be reduced to a set of $2 \mathrm{k}$ uncoupled modal equations. Then the response to an excitation can easily be calculated.

\section{COMPARISON OF EXPERIMENTAL AND THEORETICAL RESULTS}

In the analysis, uncoupled natural frequencles measured in air are used to establish the torsional spring constant $k_{i}$. Then the uncoupled natural frequency $\Omega_{i}$ and modal function $\phi_{i}$ in water for each tube in the $\mathbf{x}$ and $\mathbf{y}$ directions are calculated. Coupled natural frequencles and mode shapes are determined from Eq. (10). Once the normal modes of coupled motion are determined, tube responses to any excitation can be calculated rather easily. 


\section{A. Uncoupled Natural Frequenctes}

Uncoupled natural frequencles, modal damping ratio, and related parameters are given in Tables 1 to 6, , where the dimensionless spring constant $p_{1}$ is defined by $\frac{k_{1} l}{E_{1} I_{1}}\left(l=\right.$ tube length, $E_{1}=$ Young's modulus, and $I_{1}=$ moment of inertia): The nominal gap-to-radius ratios are given In Fig. 2. However, in the tested assemblies, the average gap-to-radius ratio at the free end is different from that at the base. In computations, the average value is used; those values are given in the tables in parentheses.

It can be seen from Tables 1-6 that the calculated values are in reasonable agreement with the experimental data. In general, the measured frequencies are somewhat lower than the calculated values; this is believed to be due to the fact that wedges are employed in experiments to hold the tubes such that the tubes will be closer to the measured tube and the added mass effect will be larger than calculated values. It is noted that the modal damping in water is much larger than that in air. Since the tubes are soldered to the base, damping is small.

\section{B. Coupled Natural Frequencies}

For a group of $k$ tubes, there are $2 k$ cuupled nacural frequencies. These coupled natural frequencies from experiments and analyses are shown in Tables $7-13$.

Theoretically, the motions for a row of tubes in the in-plane and out-of-plane are uncoupled [2]. Experimental results show that they indeed are independent of each other. Therefore, the results for the cases of tube rows are presented in two groups in the $x$ and $y$ directions.

The calculated and measured values of coupled natural frequencies agree very well. For partially submerged cases, as the fluid depth

* Tahles begin on pagc 36. 
becomes small, fluid coupling decreases and the theory and experiment do not agree very well. This is attributed to the base coupling which is not accounted for in the theory.

The damping ratio shown in Tables $7-12$ is calculated from Eq. (6) assuming that the damping coefficient $c_{i}=2 \Omega_{i}\left(m_{i}+\gamma_{1 i}\right) \zeta_{i}$, where $\zeta_{i}$ is the uncoupled modal damping ratio in water. In general, the damping ratio for coupled modes increases as the frequency increases and its magnitude is approximately the same as those for uncoupled modes.

\section{Mode Shapes}

The theoretical mode shapes for coupled modes are obtained from Eq. (10), while the experimental mode shapes are obtained using the acceleration-time traces recorded from steady-state excitation at a resonance frequency. For simplicity, only three typical cases are presented in Figs. 10-12, where the experimental frequencles are the driving frequencies. The arrows on the figures Indicate the relative position for each tube, and. the lengths of the lines represent the magnitudes of tube displacements. Comparing the theoretical and experimental results, one can see that the agreement is very good. There are a few exceptions. For example in the case of 5 tubes, tube 1 has a relatively large component In the in-plane direction. This may be associated with the fact that the tubes may not be precisely parallel or the principal axes of tube 1 may not be in the $\mathrm{x}$ and $\mathrm{y}$ directions. The other examples are those of modes 3 and 5 for 3 tubes. In those modes, the theoretical and experimental results do not agree we1l. This can be explained easily. The tube assembly is excited at tube 3 in the y direction. However, corresponding to those modes, tube 3 has a very small displacement component; 1.e., the tube assembly is not easily excited by applying force to tube 3 . At those frequencies, not only those natural modes are excited, but other modes also 
are excited. Therefore, the experimental results cannot represent the actual modes but are combinations of several natural modes. If the assembly were exclted at the other tubes, correct experimental results would have been obtalned for those two modes. Modes 4 and 6 for four tubes are also not in agreement; this is attributed to the same reason. D. Steady-State Responses

The excitation force is proportional to the input current. Its magnitude is smali and not easily calibrated. Therefore, the excitation force is not measured directly in experiments. In order to compare the theoretical and experimental results, the magnitude of the force used in the analysis is obtained using the experimental response values for the tube excited at a frequency equal to $50 \mathrm{~Hz}$; $1 . e .$, the analytical and experimental accelerations at $50 \mathrm{~Hz}$ are made equal for the tube excited. The results are presented in Figs. 13 and 14 for two typical cases. It can be seen that the agreement is very good. Because of fluid coupling, those tubes not directly excited have large response in the frequency band containing coupled natural frequencies of the system.

\section{E. Transient Responses}

Ani example of the translent responses for 5 tubes is presented in Fig. 15. Similar results are obtained for other cases. For conciseness, those results are not presented here. The transient responses are obtained by plucking. Since the excitation force is not well defined, it is difficult to compare with analytical calculations. Therefore, no analytical results are presented for transient responses.

Based on the experimental results we note that there exist beating phenomena for all tubes. This occurs because there are five natural frequencies which are relatively close to one another. The disturbance was 
given to tube 1, it has a large response instantly. On the other hand, the peak amplitudes occur later for other tubes; it takes time to develop large tube oscillations.

VI. EFFECTS OF VARIOUS PARAMETERS ON TUBE RESPONSES

A. Gap-to-Radius Ratio

For a group of tubes vibrating in a liquid, the frequency band of coupled modes [2] becomes wider as the gap-to-radius ratio (G/R) decreases. This can be seen clearly from Table 8 for 3-tube arrays. Based on the experimental data, the limits of the frequency band are $64.02 \mathrm{~Hz}$ to $71.52 \mathrm{~Hz}$ for $G / R=2.0$, and $57.42 \mathrm{~Hz}$ to $74.47 \mathrm{~Hz}$ for $\mathrm{G} / \mathrm{R}=0.5$. Other tube arrays also show similar effect. This is attributed to fluid inertia coupling; as the gap decreases, the fluld coupling becomes larger.

\section{B. Flat Wall}

Figure 16 shows the experimental data for the natural frequencies of coupled modes as a function of the ratio of the gap to tube radius $\left(G_{w} / R\right)$. As $G_{w} / R$ decreases, the frequency band becomes wider; the wall effect is similar to that of reducing the tube pitch (G/R).

C. Eccentricity of Outside Container

Figure 17 shows the effect of the eccentricity $\left(G_{e} / R\right)$ on natural frequencies (experimental data). Most of the natural frequencies decrease with increasing $G_{e} / R$, but the fourth mode increases. However, the effect is small.

\section{Water Depth}

The variations of coupled natural frequencles (experimental data) with fluid depth are shown in Fig. 18. Two effects are observed as the fluid depth increases: (1) the frequency band becomes wider, (2) the coupled natural frequencies become lower. 


\section{E. Fluid Viscosity}

The natural frequencles of uncoupled and coupled vibrations and damping are shown in Table 14 and 15 for the 4-tube array vibrating in water and mineral oil (specific gravity $=0.935$, and viscosity $=41 \mathrm{cp}$ ). The effect of fluid viscosity on damping is significant, but its effect on natural frequencies is small. The role of fluid viscosity on coupled vibration of multiple tubes is similar to that of two coaxial shells [5].

\section{F. Uncoupled Vibration}

Figures 19 and 20 show the steady-state responses of two-tube arrays under two different conditions: (a) all other tubes are held rigid except the one being excited; and (b) all tubes are free to vibrate. It can be seen that the tube responds differently under two different conditions. This illustrates that using uncoupled modes to study multipletube problem may result in error.

\section{CONCLUSIONS}

Four series of tests have been performed for uncoupled and coupled vibrations of tube bundles in 1iquids. The experimental data and analytical results for natural frequencies, mode shapes, and forced responses are in good agreement. Therefore, the analytical method developed earlier $[1,3]$ is basically sound and can be used with confidence for tube bundles vibrating in liquid.

Although extensive studies of vibration of tube bundles have been reported, this study is the first. knnwn systematic expcrimental investigation to obtain the detailed information of coupled tube/fluid vibration. In the past, predictions of tube responses in liquid were frequently based on uncoupled mode of a single tube. From the analytical and experimental results presented in this paper, it is clear that in predicting tube bundle responses coupled modes should be employed. 


\section{ACKNOWLEDGMENTS}

This work was performed under the sponsorship of the Division of Reactor Development and Demonstration, U. S. Energy Research and Development Administration.

Credit is due to Mr. H. N. Cornelius for his help in performing the test work.

\section{REFERENCES}

1. Chen, S. S., "Vibration of Nuclear Fuel Bundles," Nucl. Eng. and Design 35, 1975, pp. 399-422.

2. Chen, S. S., "Vibrations of a Row of Circular Cylinders in a Liquid," J. Eng. for Industry $\underline{97}, 1975$, pp. 1212-1218.

3. Chung; H., and Chen, S. S., "Vibration of a Group of Circular Cylinders in a Confined Fluid," Argonne National Laboratory, Technical Memorandum ANL-CT-76-25; Also to appear in J. Appl. Mech., ASME.

4. Chen, S. S., and Jendrzejczyk, J. A., "Dynamic Responses of Heat Exchanger Tube Banks," Argonne National Laboratory, Technical Memorandum ANL-CT-76-30, 1976.

5. Yeh, T. T., and Chen, S. S., "Dynamics of Two Coaxial Cylindrical Shells Containing Viscous Fluid," Argonne National Laboratory, Technical Memorandum ANL-CT-76-48. 


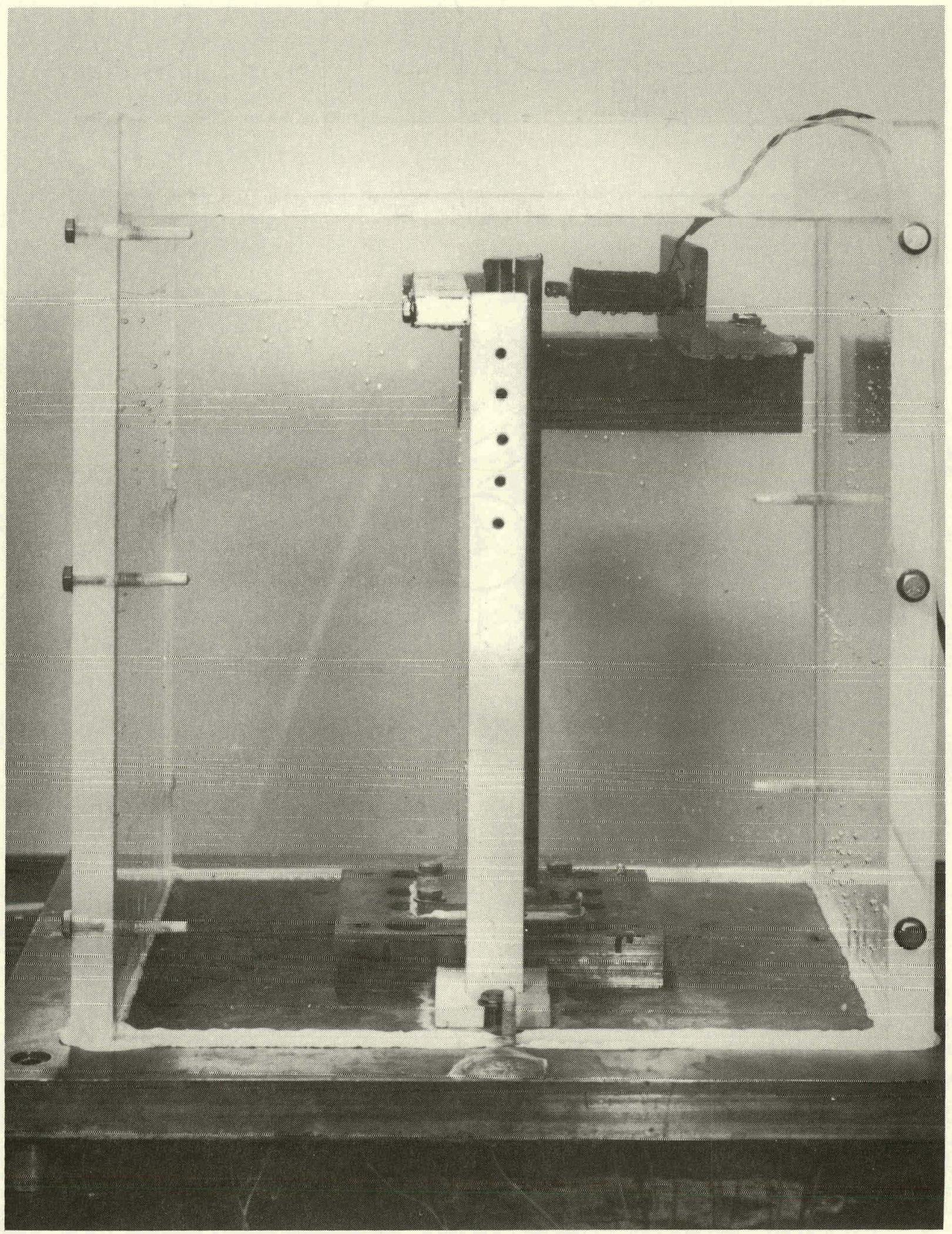

Fig. 1. 'lest assembly 

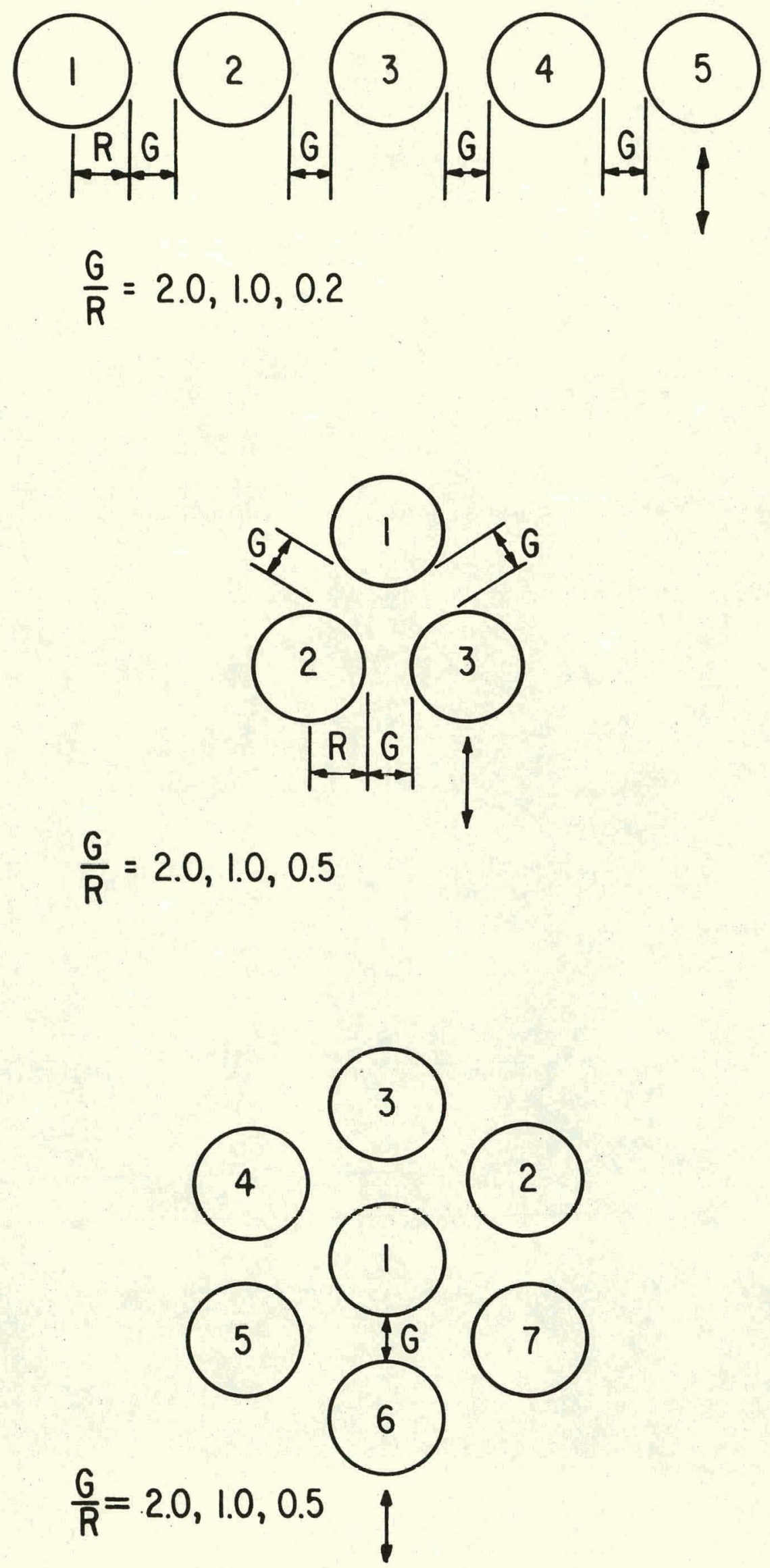

Fig. 2a. Tube arrangement 

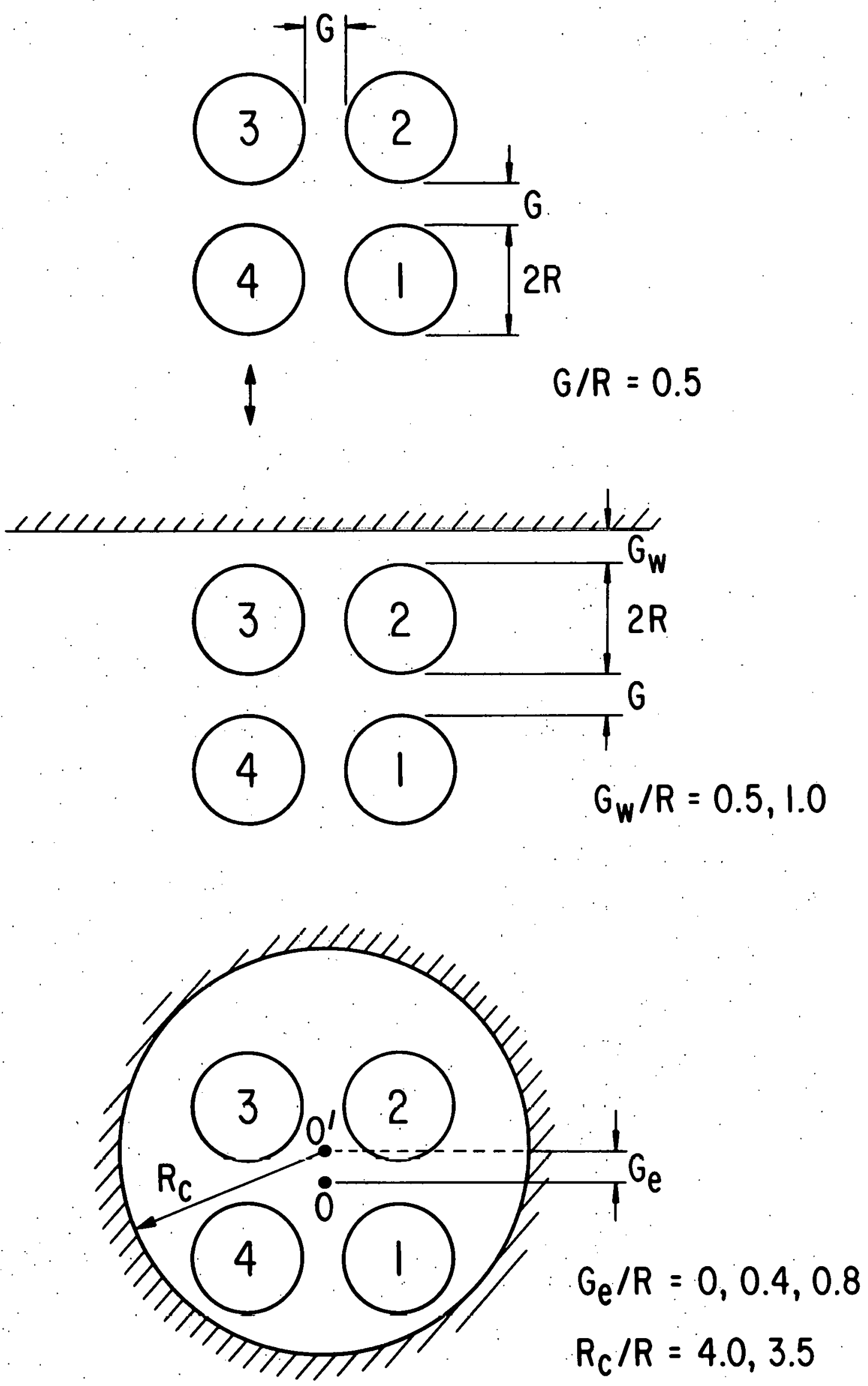

Fig. 2b. Tube arrangement 


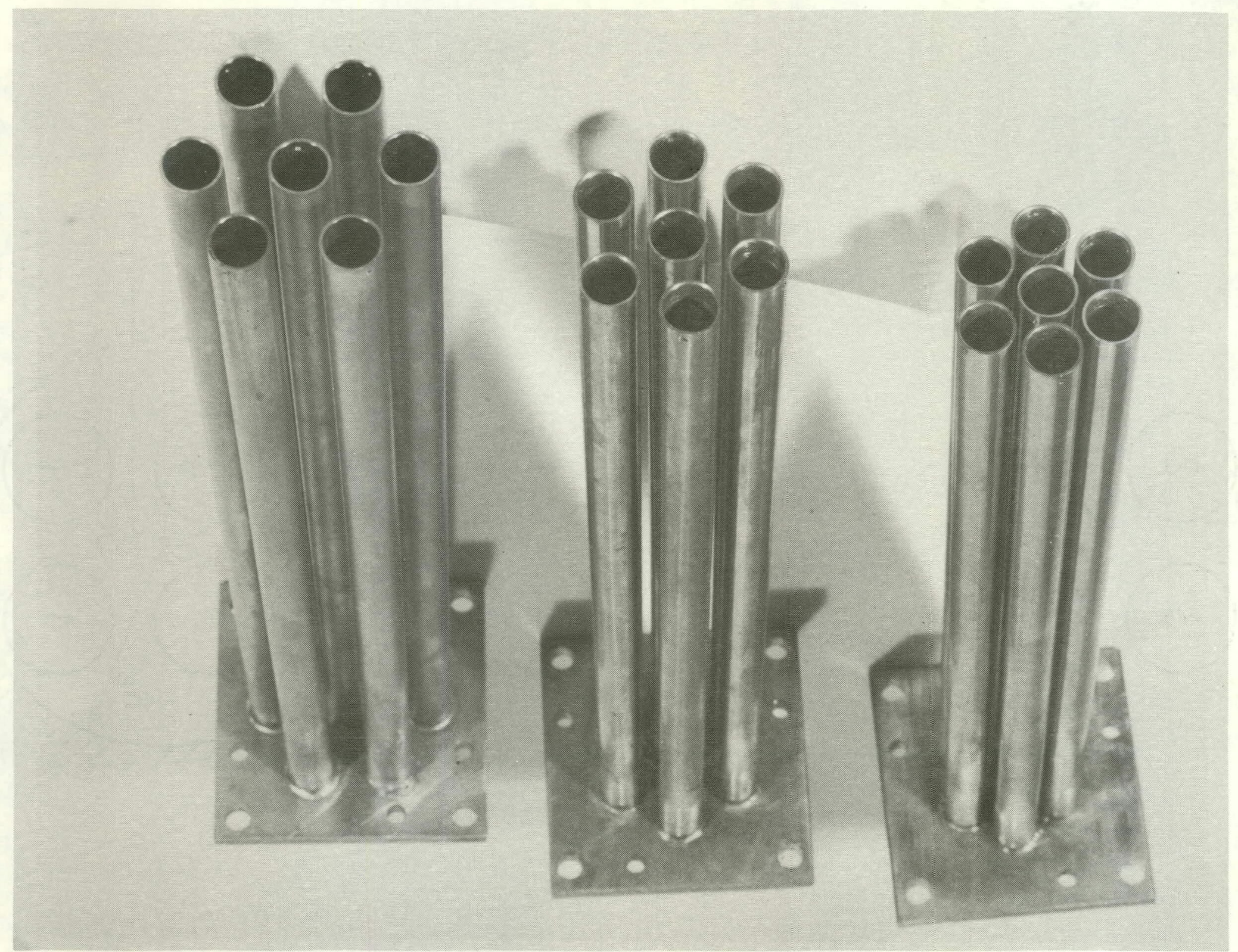

Fig. 3. Test elements 


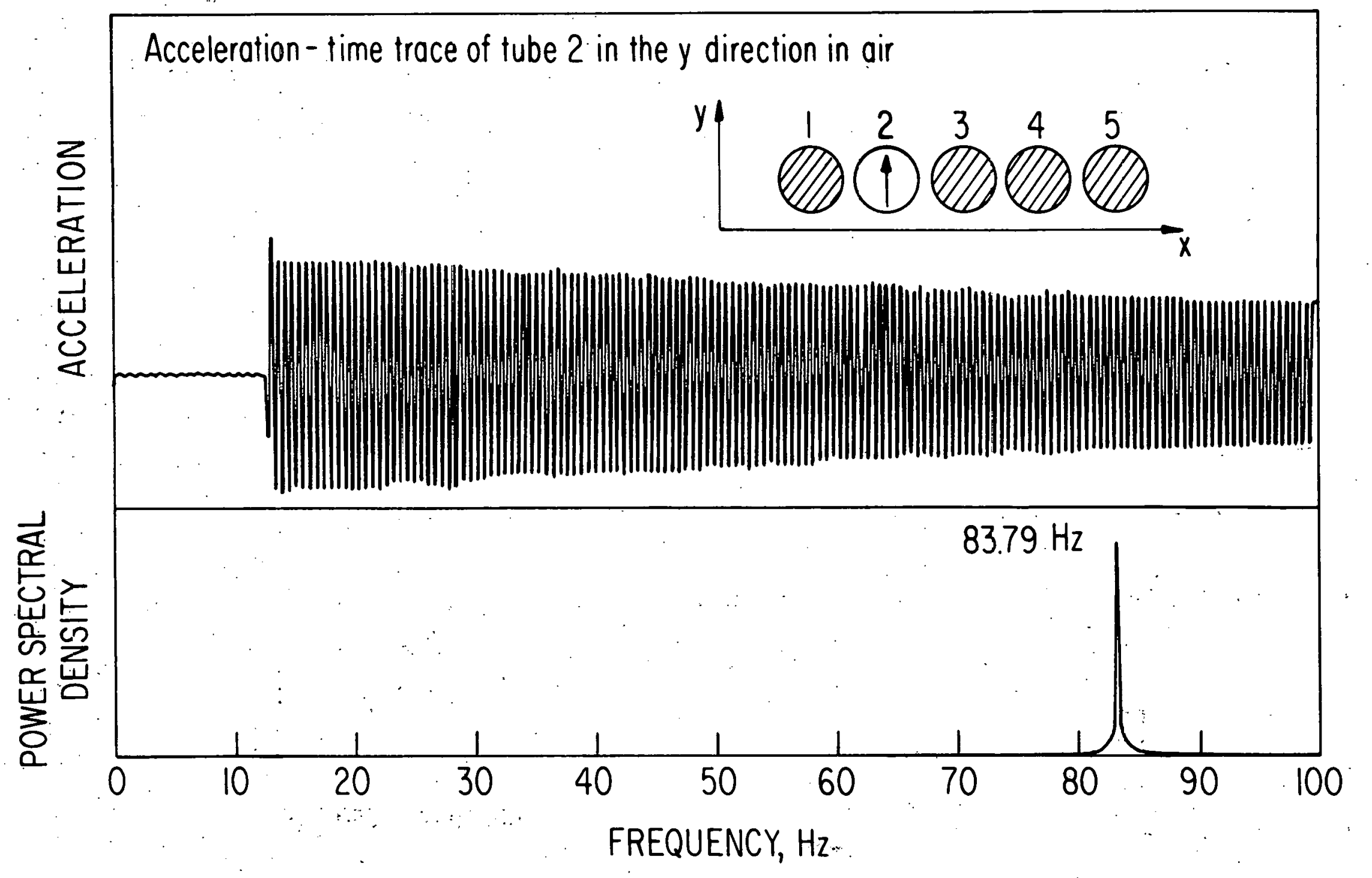

Fig. 4. Acceleration-time trace and power spectral density of tube acceleration for tube 2 in air $(G / R=0.25)$ 


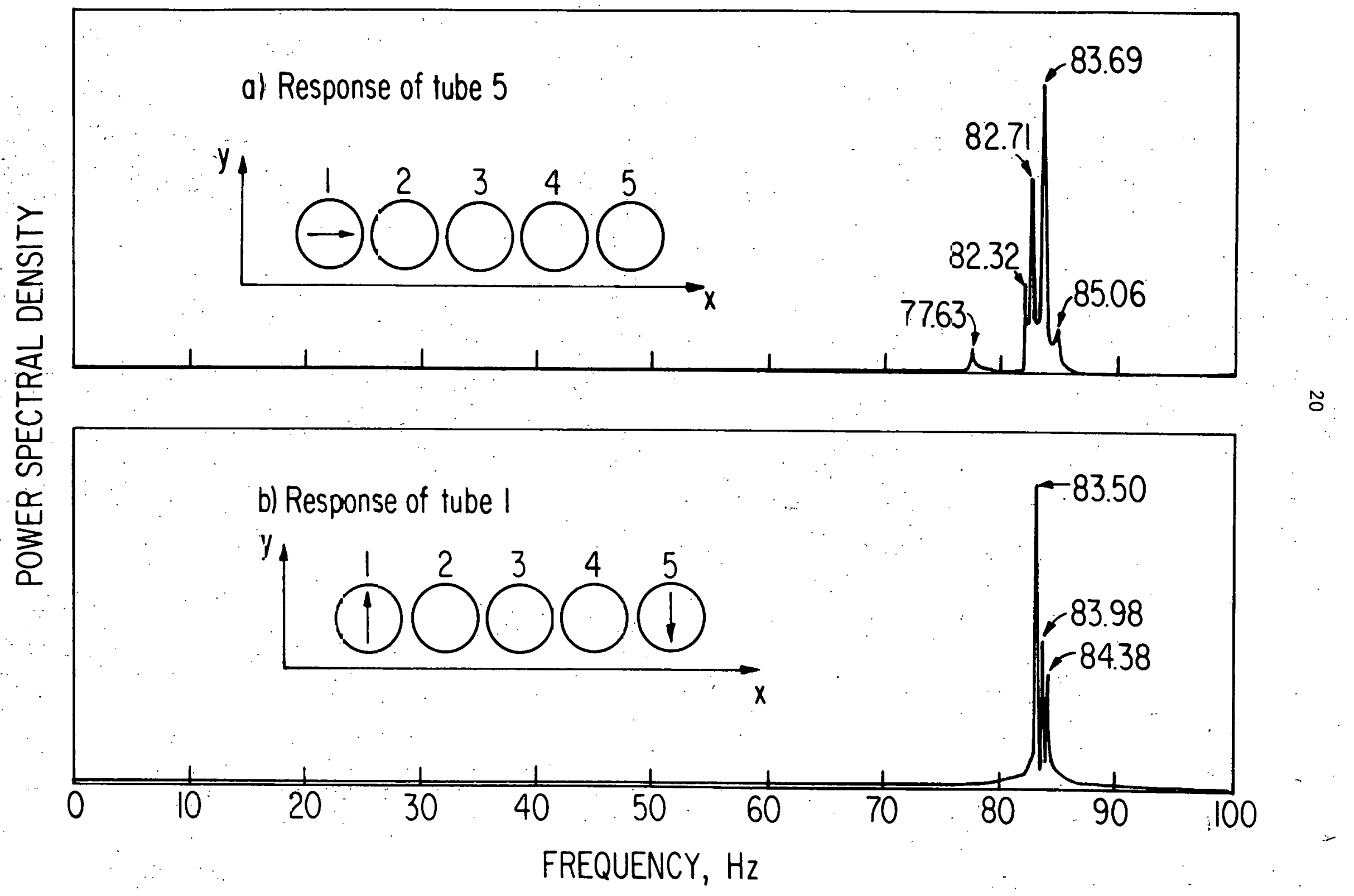

Fig. 5. Power spectral density of tube acceleration for a row of five tutes in air $(G / R=0.25)$ 


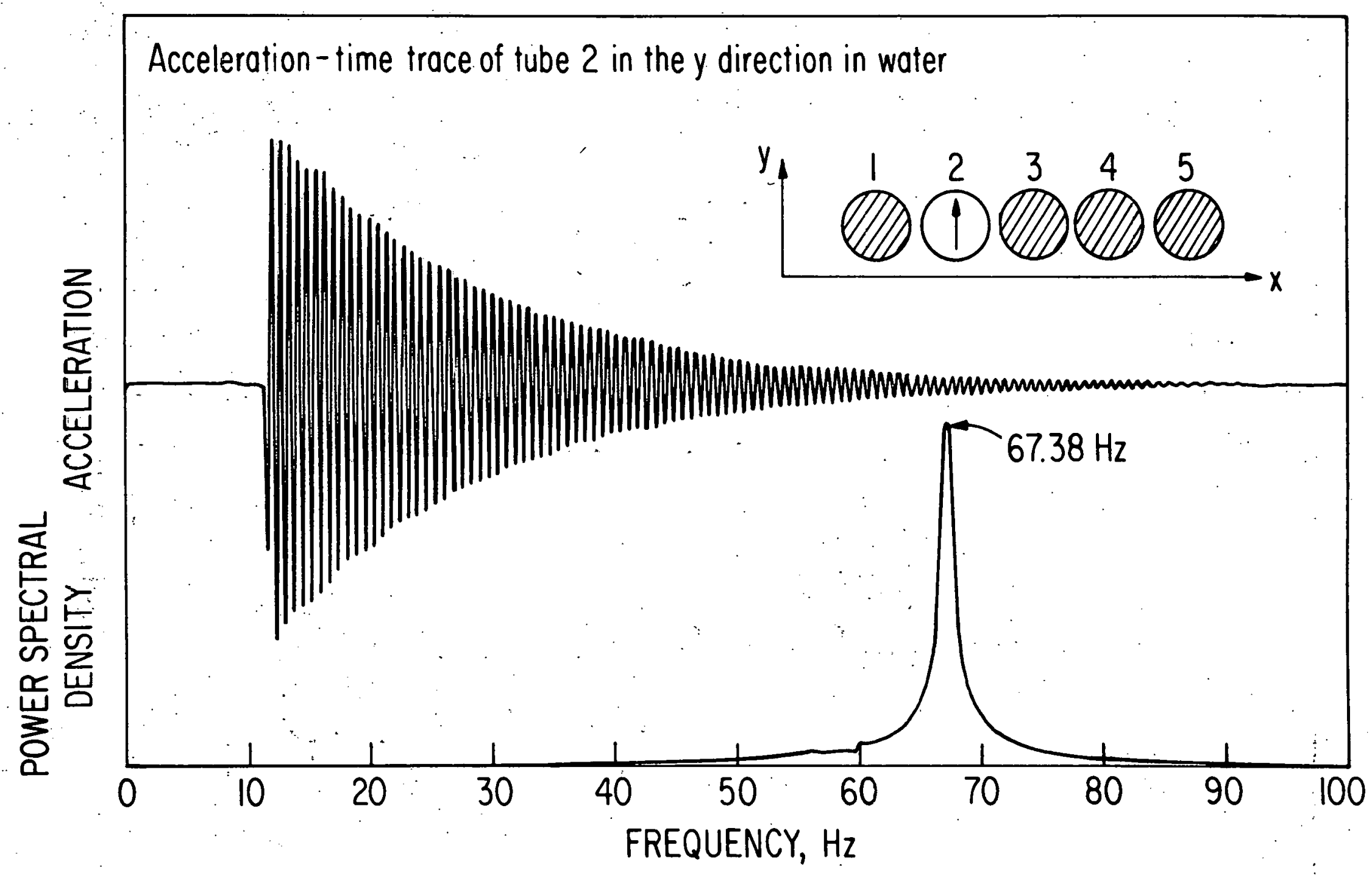

Fig. 6. Acceleration-time trace and power spectral density of acceleration for tube 2 in water $(G / R=0.25)$ 


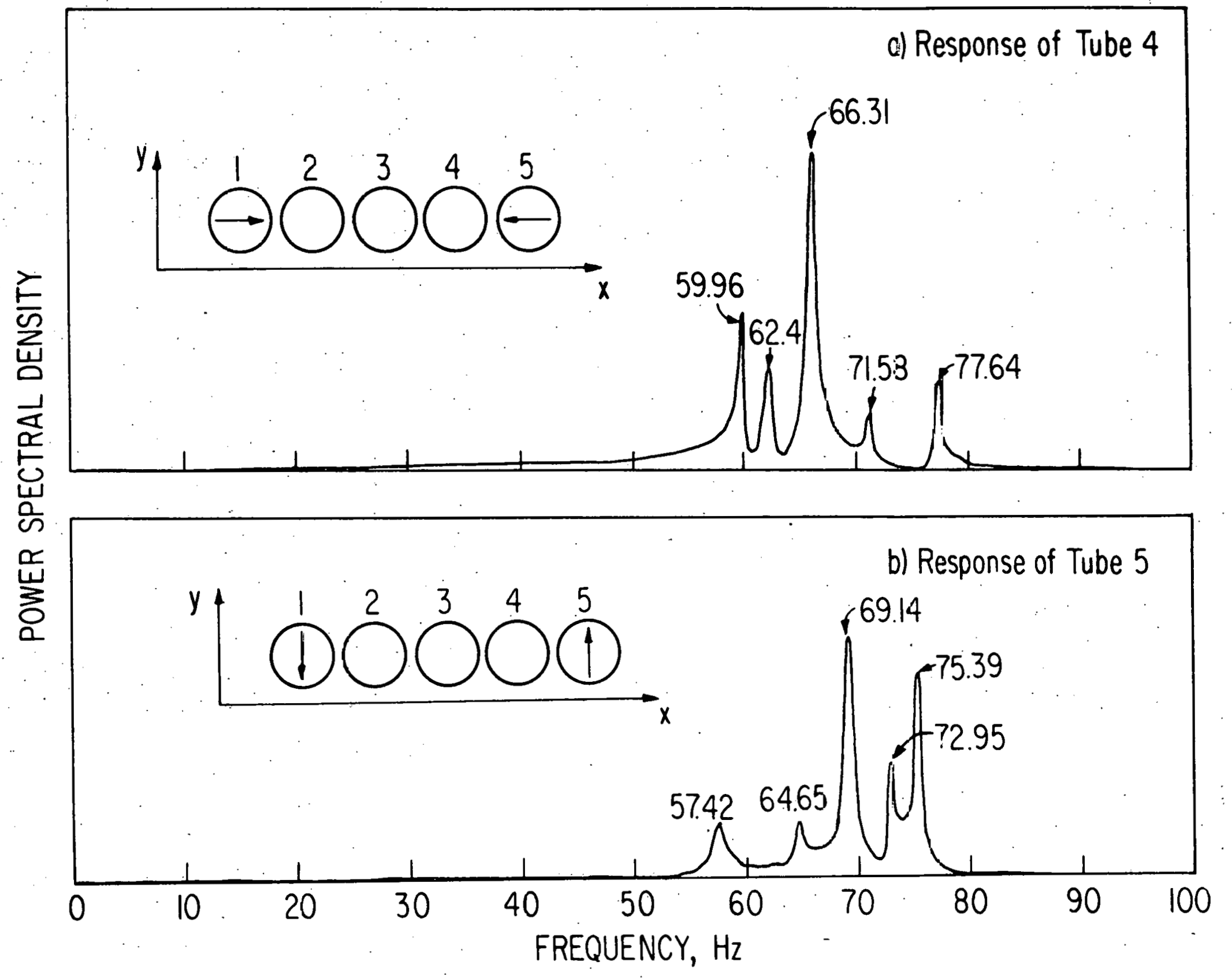

Fig. 7. Power spectral density of tube acceleration in water $(G / R=0.25)$ 


\section{MATHEMATICAL MODEL}

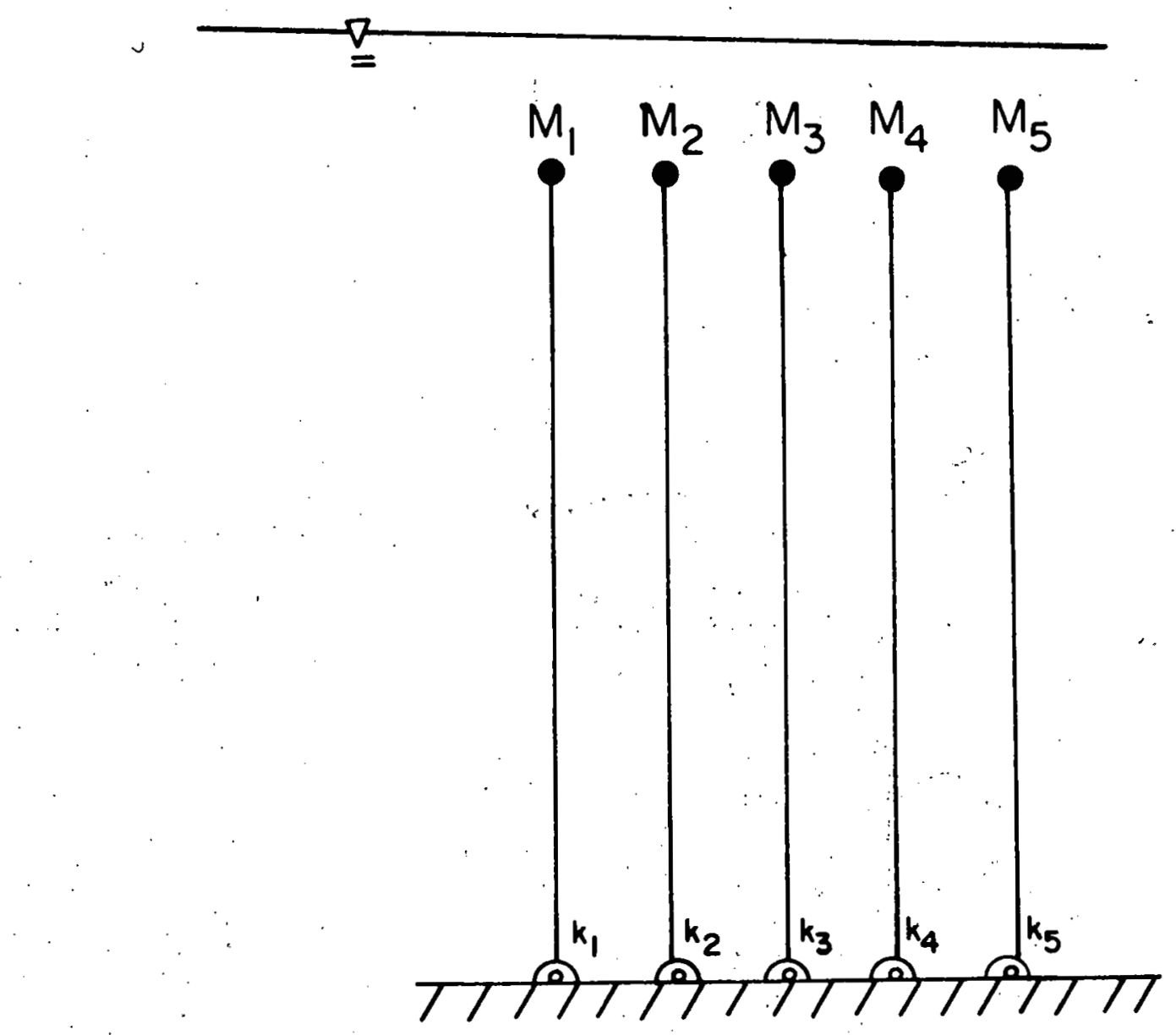

$$
\begin{aligned}
M_{i} & =\text { CONCENTRATED MASS } \\
k_{i} & =\text { SPRING CONSTANT }
\end{aligned}
$$

Fig. 8. Mathematical model used in analysis 


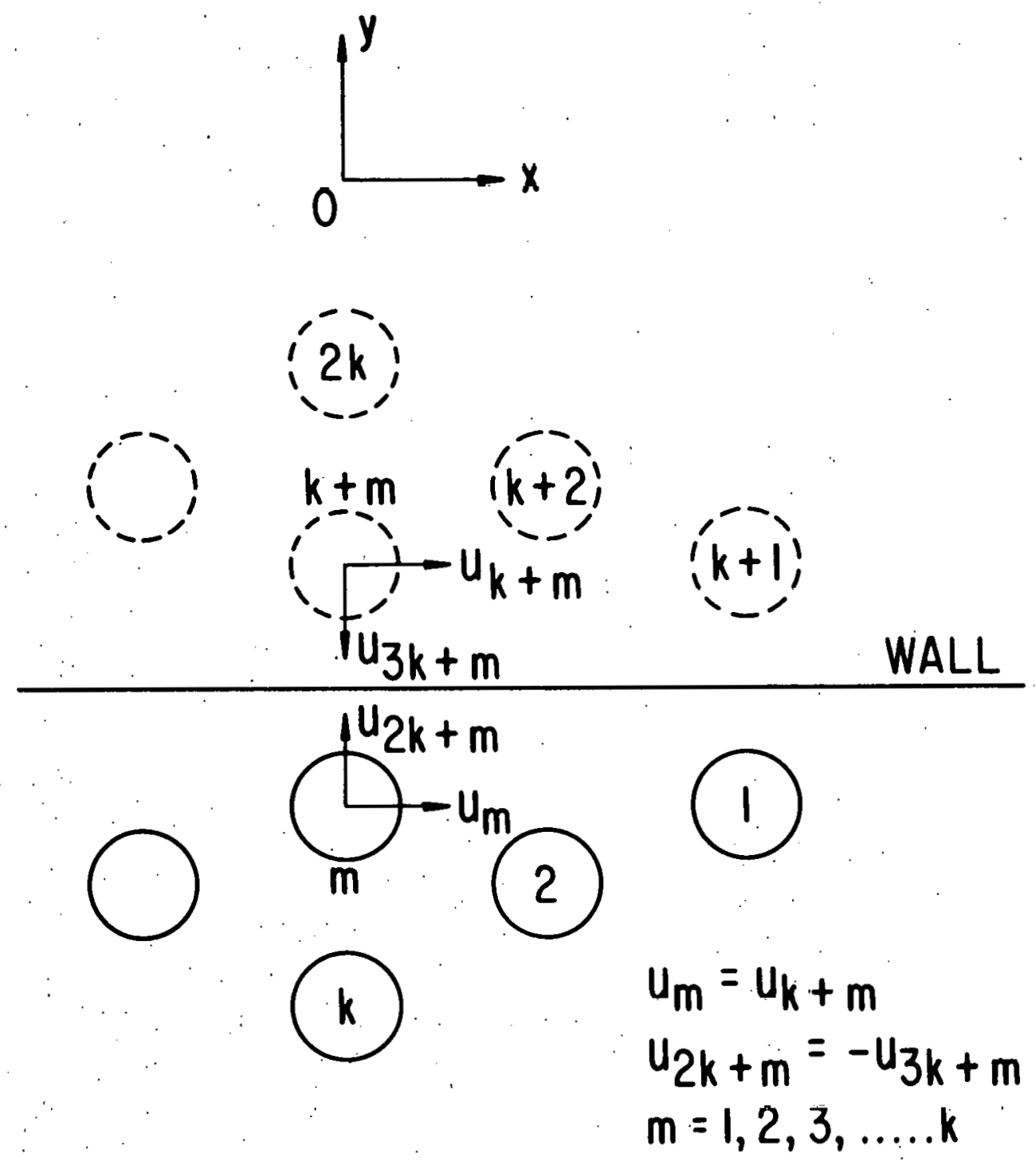

Fig. 9. Tube array near a. wall 
EXPERIMENT

THEORY

| $57.3 \mathrm{OHz} /\|\|{ }^{56.45 \mathrm{~Hz}}+|| 1 \mid$

$264.65 \mathrm{~Hz} /|1|+64.56 \mathrm{~Hz}+1+1 \mid$

$369.14 \mathrm{~Hz} / 1 / 1 \mid 69.67 \mathrm{~Hz} / 1+1$

$42.45 \mathrm{~Hz} /|1||73.79 \mathrm{~Hz}|+1 \mid+$

5. $75.39 \mathrm{~Hz})|||+75.65 \mathrm{~Hz}|+\mid+1$

Fig. 10. Mode shapes of a row of 5 tubes with $G / R=0.25$ 
EXPERIMENT

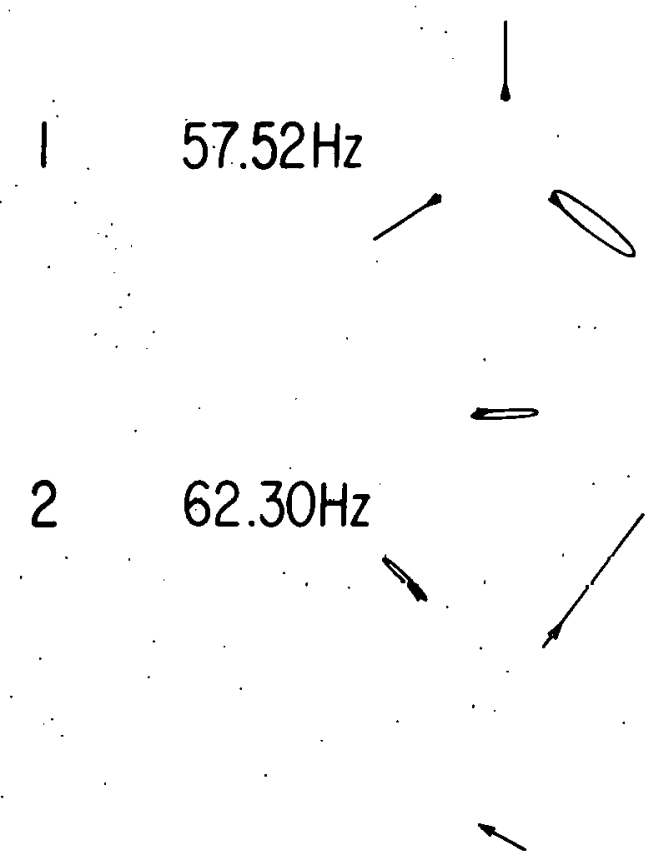

$3 \quad 64.84 \mathrm{~Hz}$

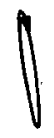

$4 \quad 70.22 \mathrm{~Hz}$
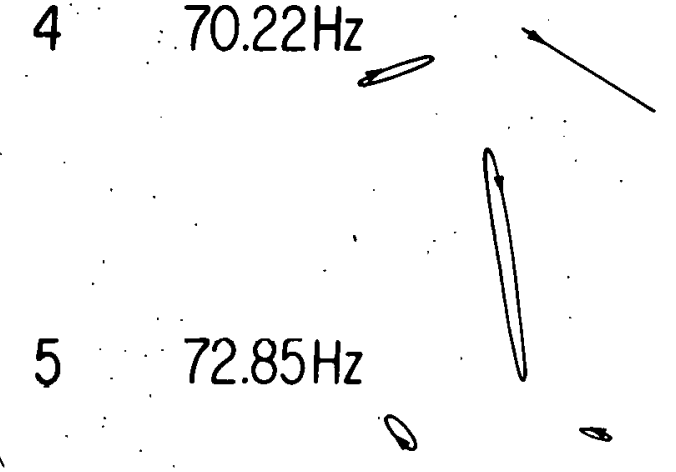

$\begin{array}{lll}6 & 74.5 \mathrm{~Hz}\end{array}$

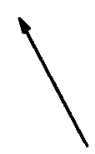

\section{THEORY}

$58.15 \mathrm{~Hz}$

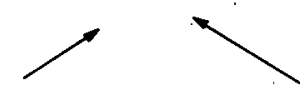

$62.32 \mathrm{~Hz}$

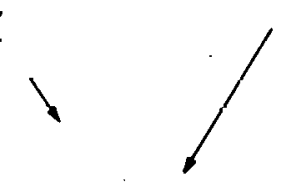

$64.86 \mathrm{~Hz}$
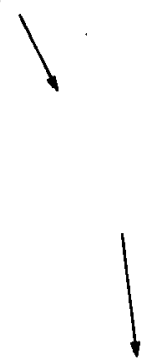

$70.14 \mathrm{~Hz}$

$72.66 \mathrm{~Hz}$
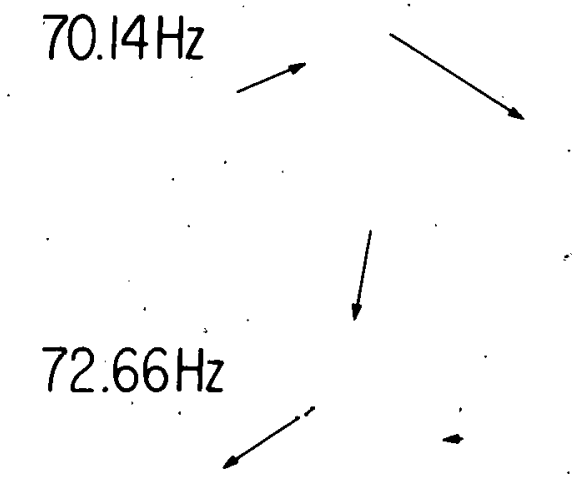

$74.32 \mathrm{~Hz}$

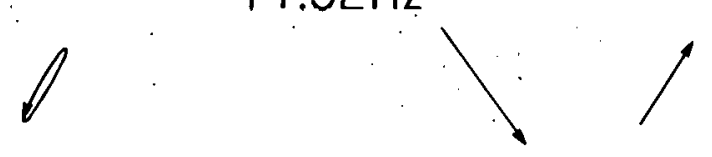

Fig. 11. Mode shapes of a group of 3 tubes with $G / R=0.5$ 


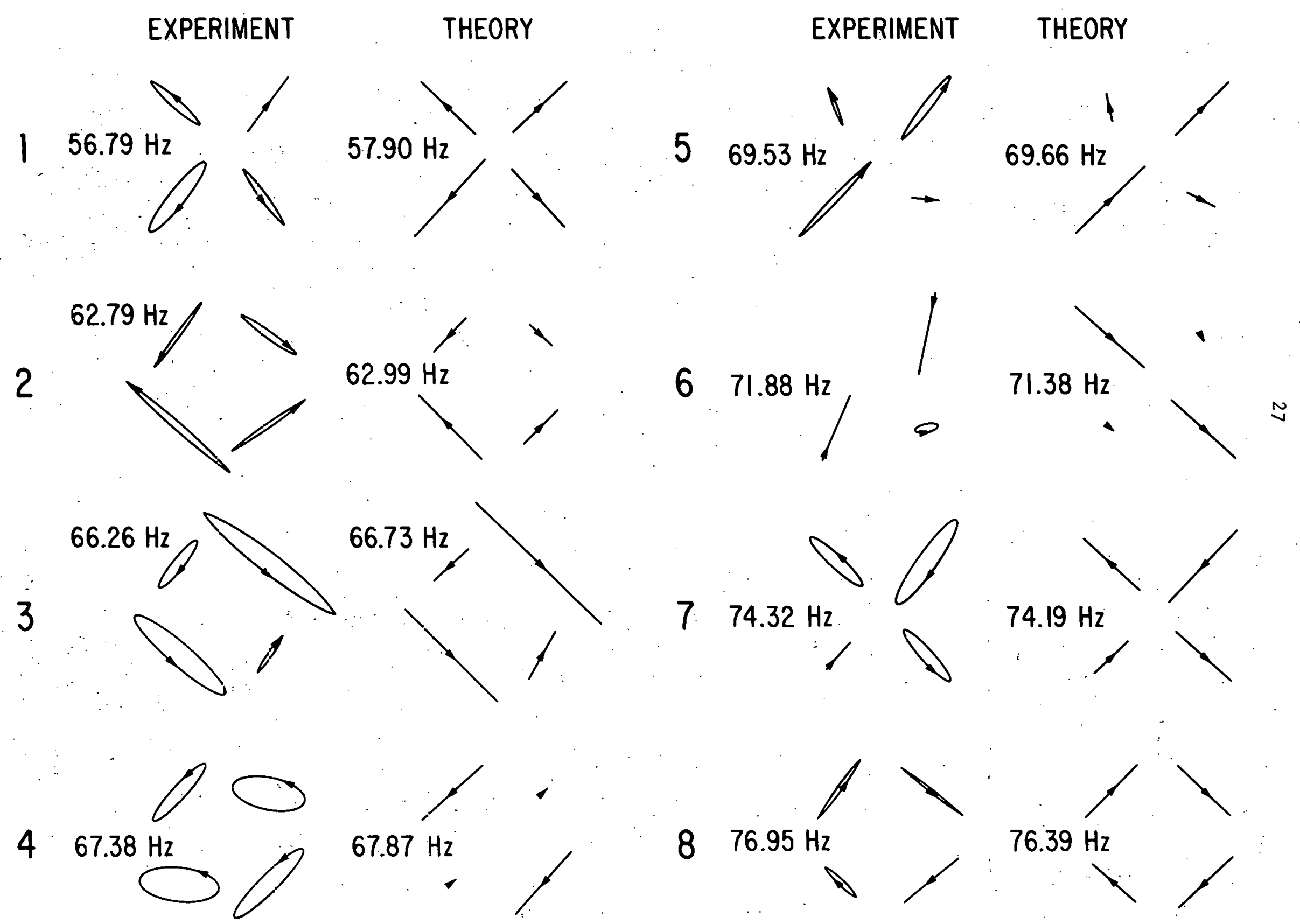

Fig. 12. Mode shapes of a group of four tubes in unconfined water 
EXPERIMENT
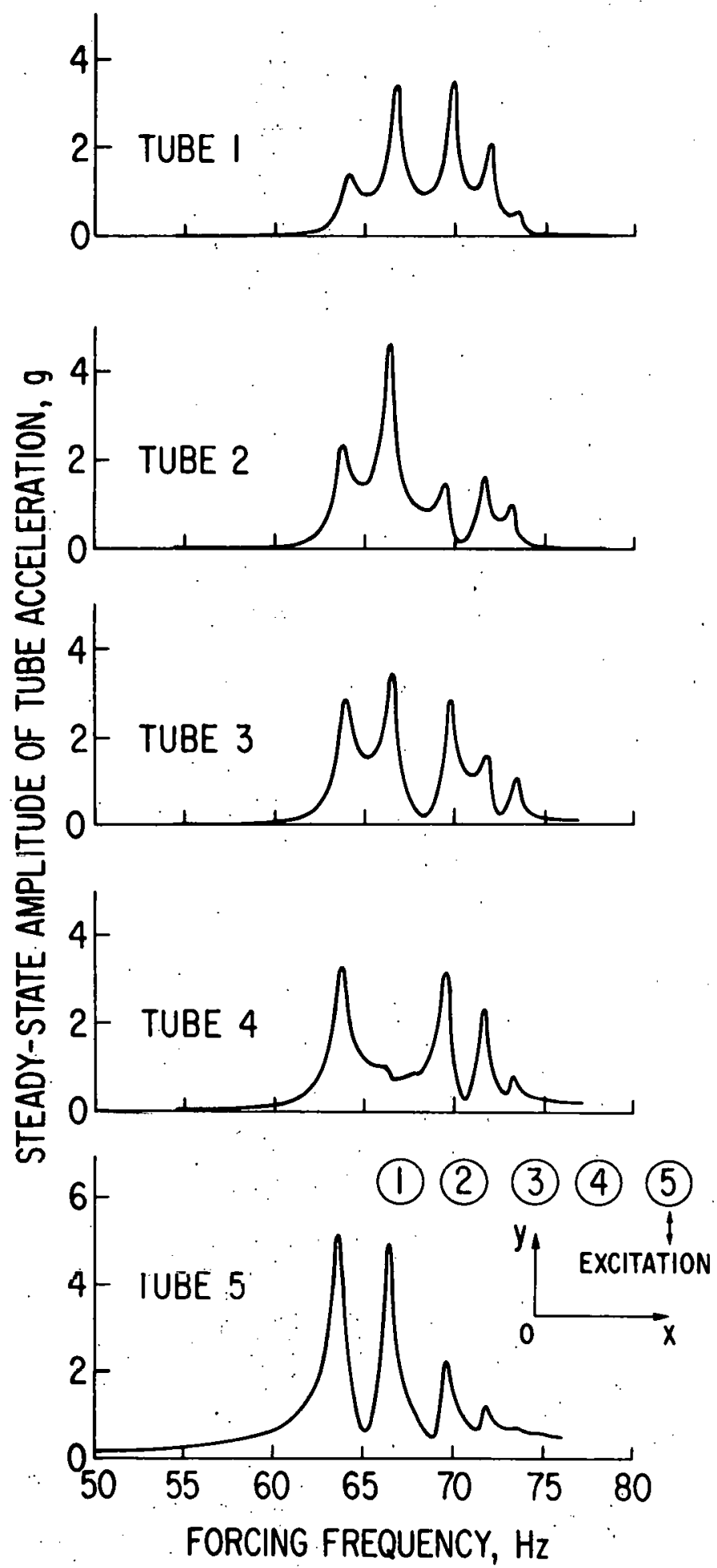

THEORY
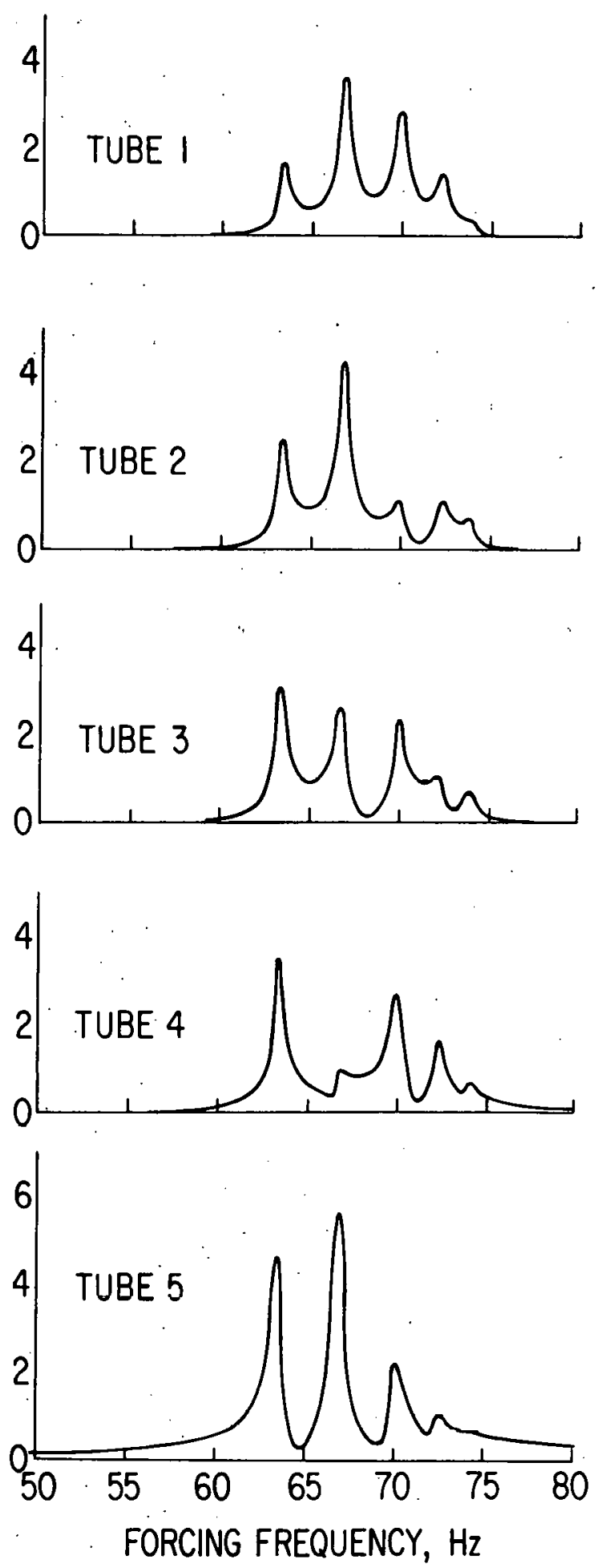

Fig. 13. Steady-state responses of a row of 5 tubes to an excitation on tube 5 with $G / R=1.0$ 
EXPERIMENT
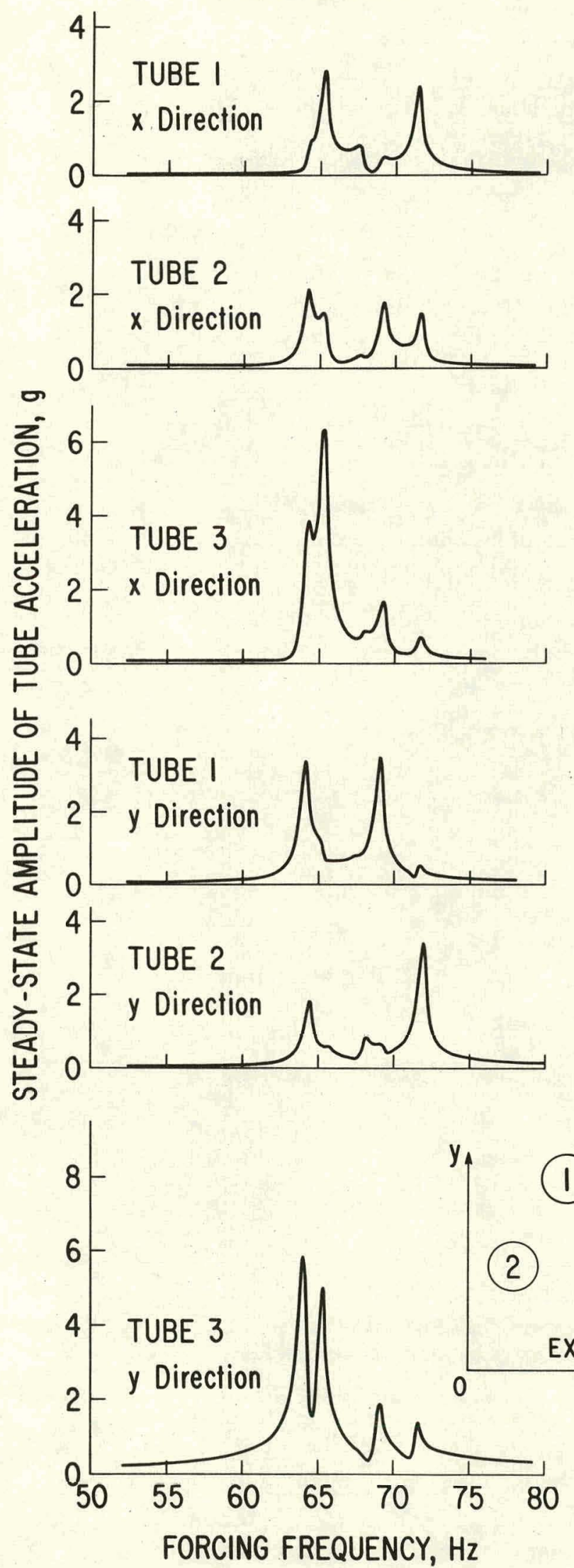

THEORY
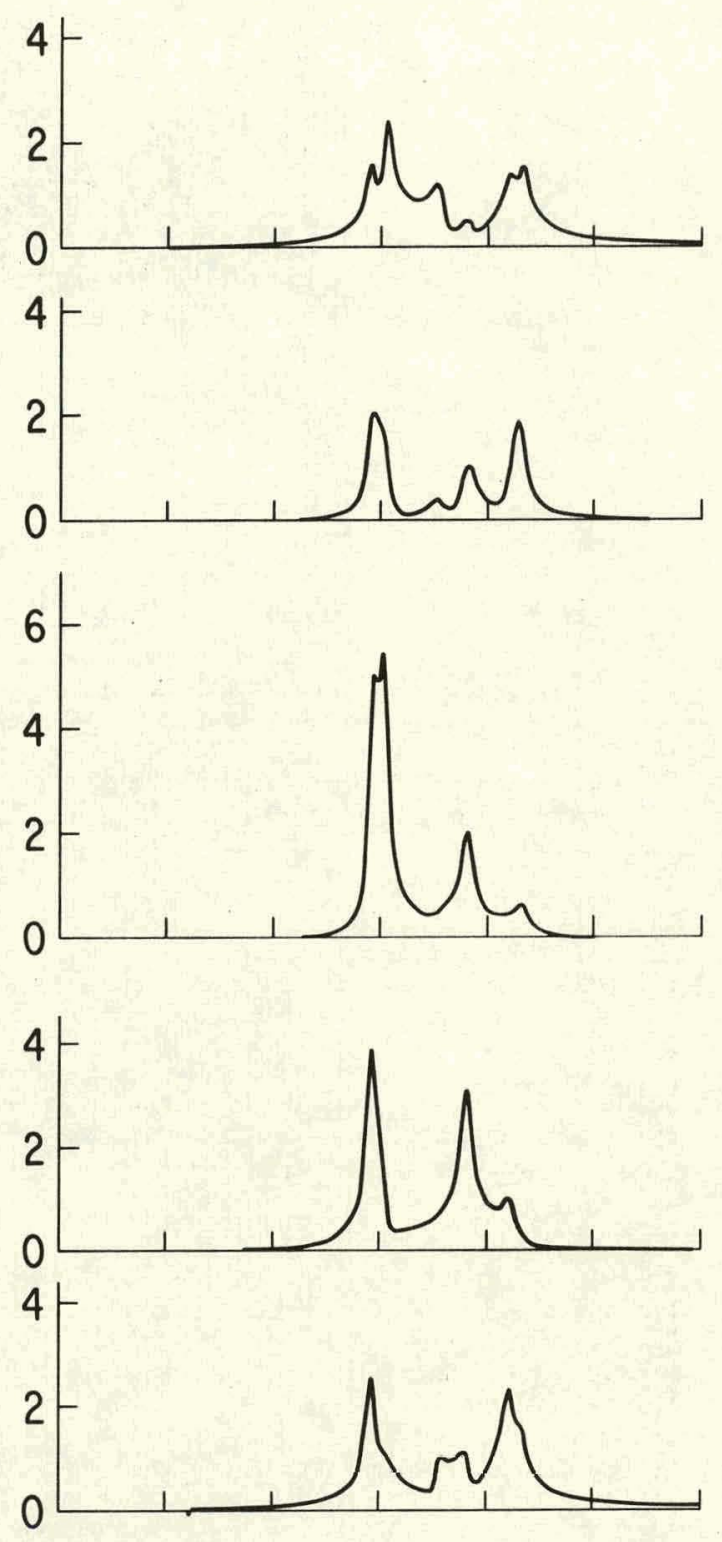

(1)

(3)

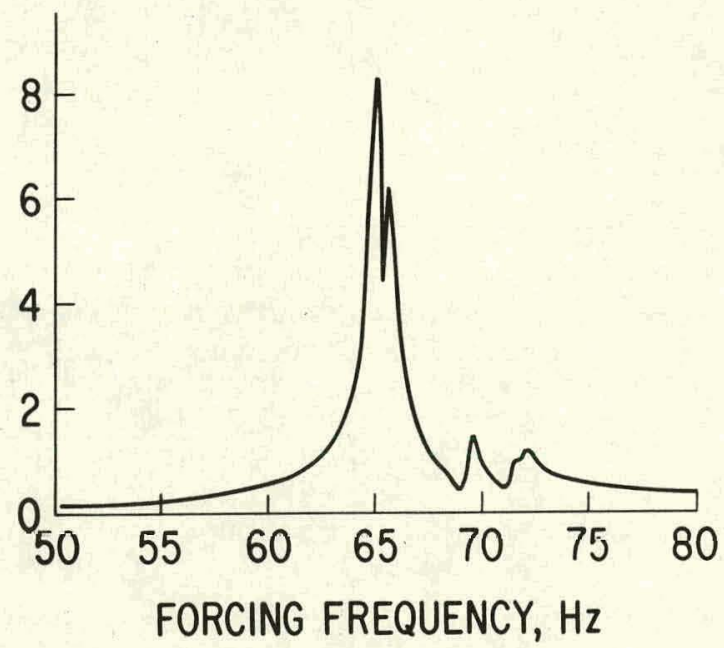

Fig. 14. Steady-state responses of a group of 3 tubes to an excitation on tube 3 with $G / R=2.0$ 


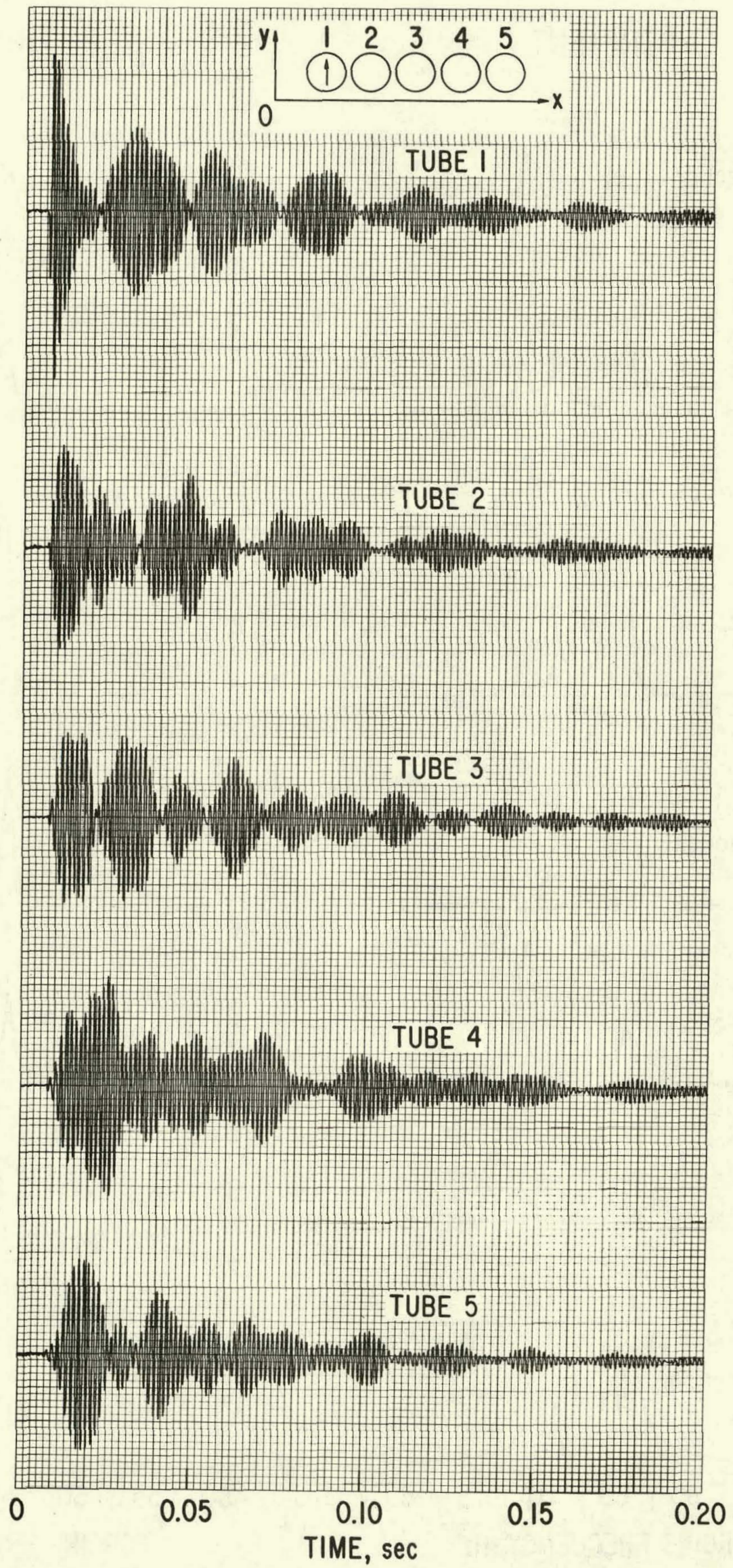

Fig. 15. Acceleration-time traces of a row of 5 tubes to an initial disturbance on tube 1 with $G / R=0.2$ 


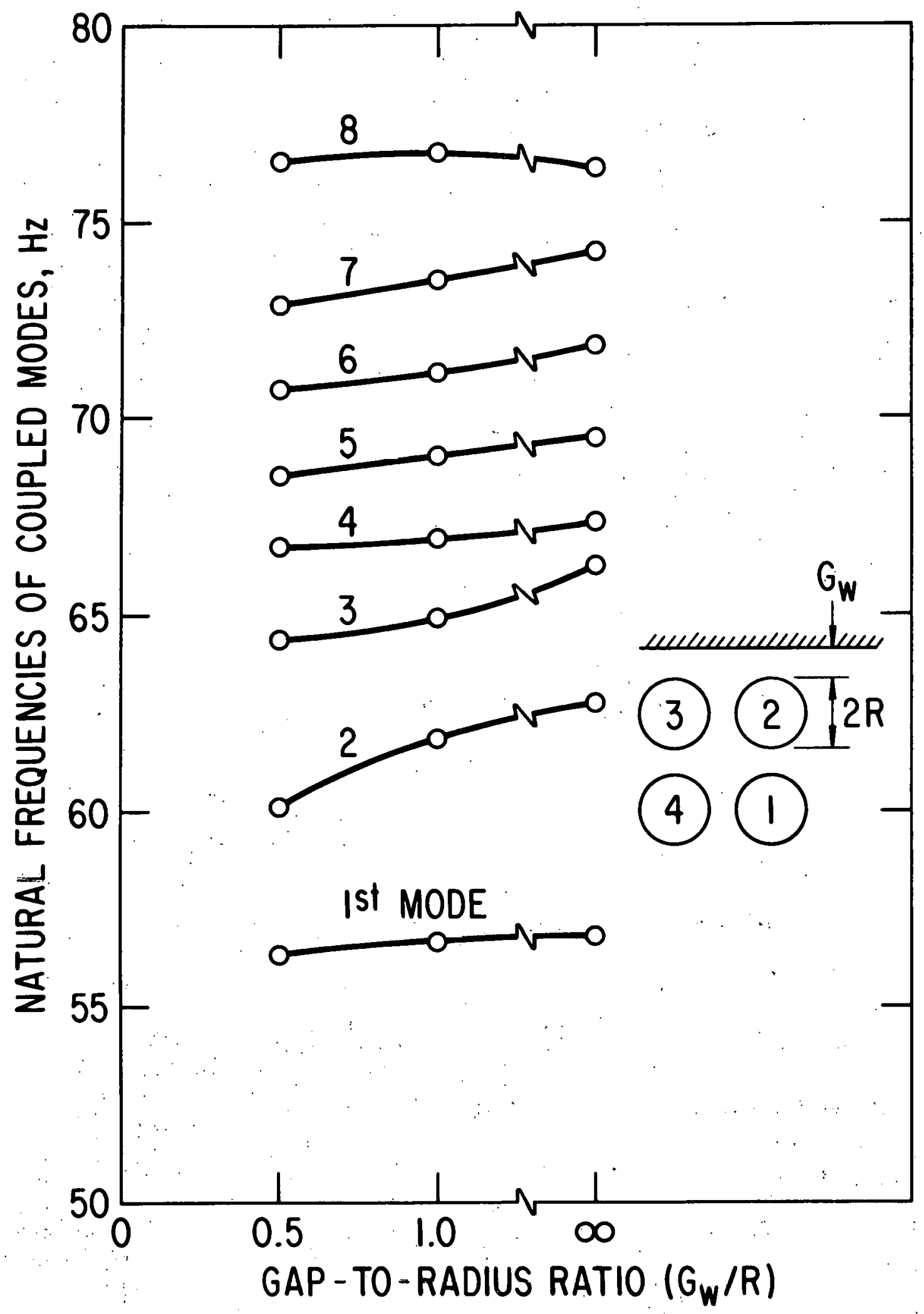

Fig. 16. Natural frequencles as a function of the gap to radius ratio, $G_{W} / R$. 


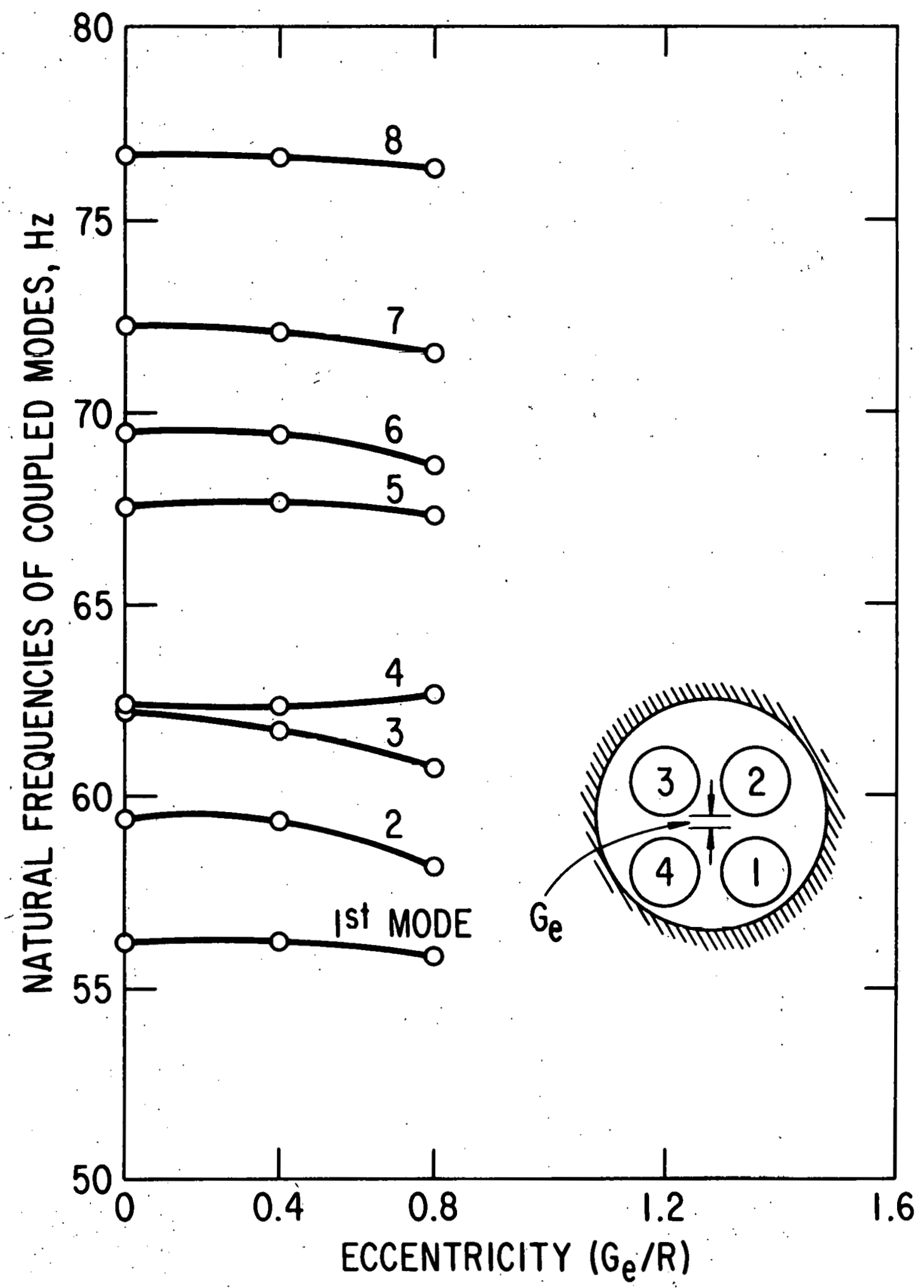

Fig. 17. Natural frequencles as a function of the eccentricity, $G_{e} / R$ 


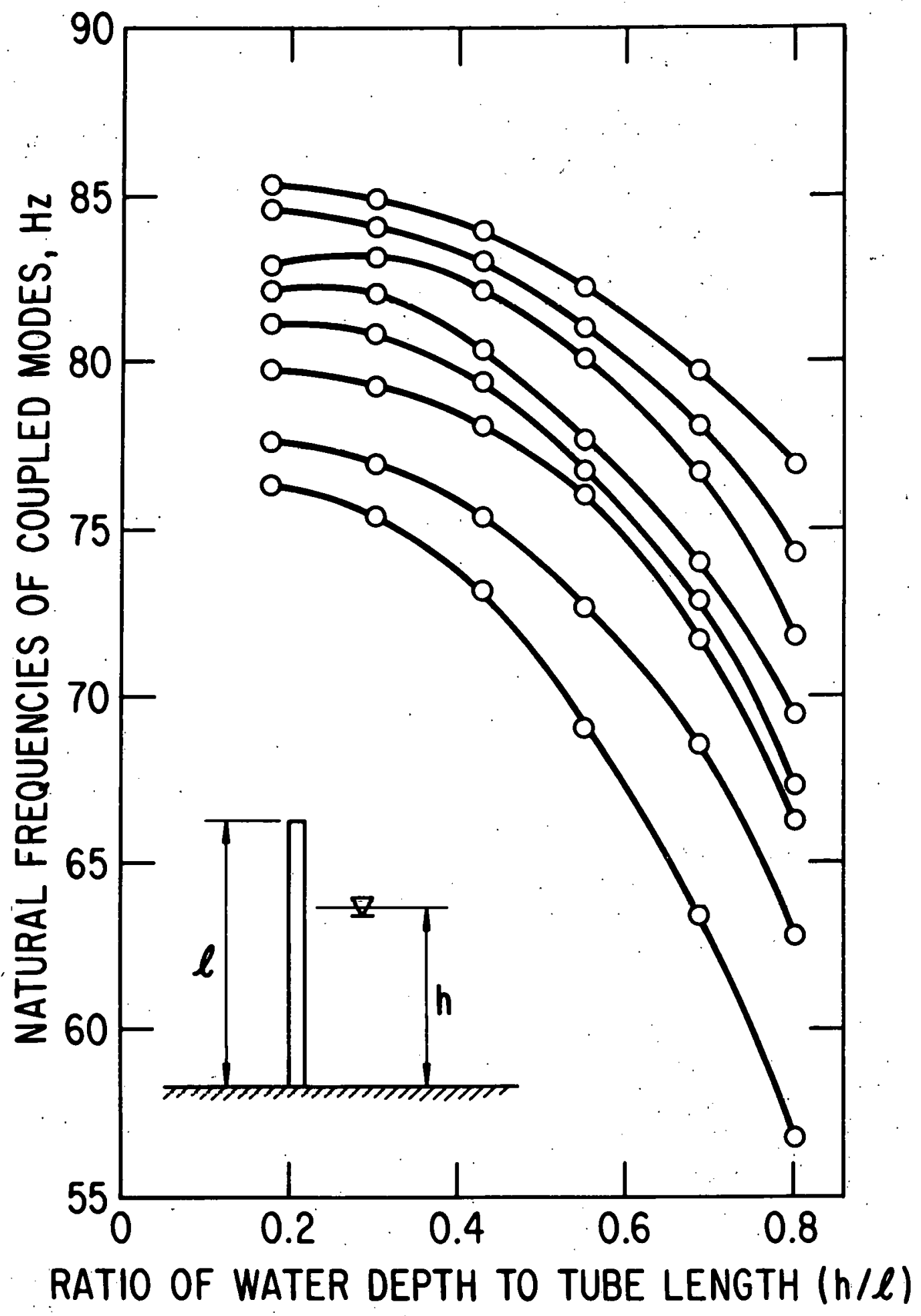

Fig. 18. Natural frequencies as a function of the ratio of water depth to tube length $(h / l)$ 


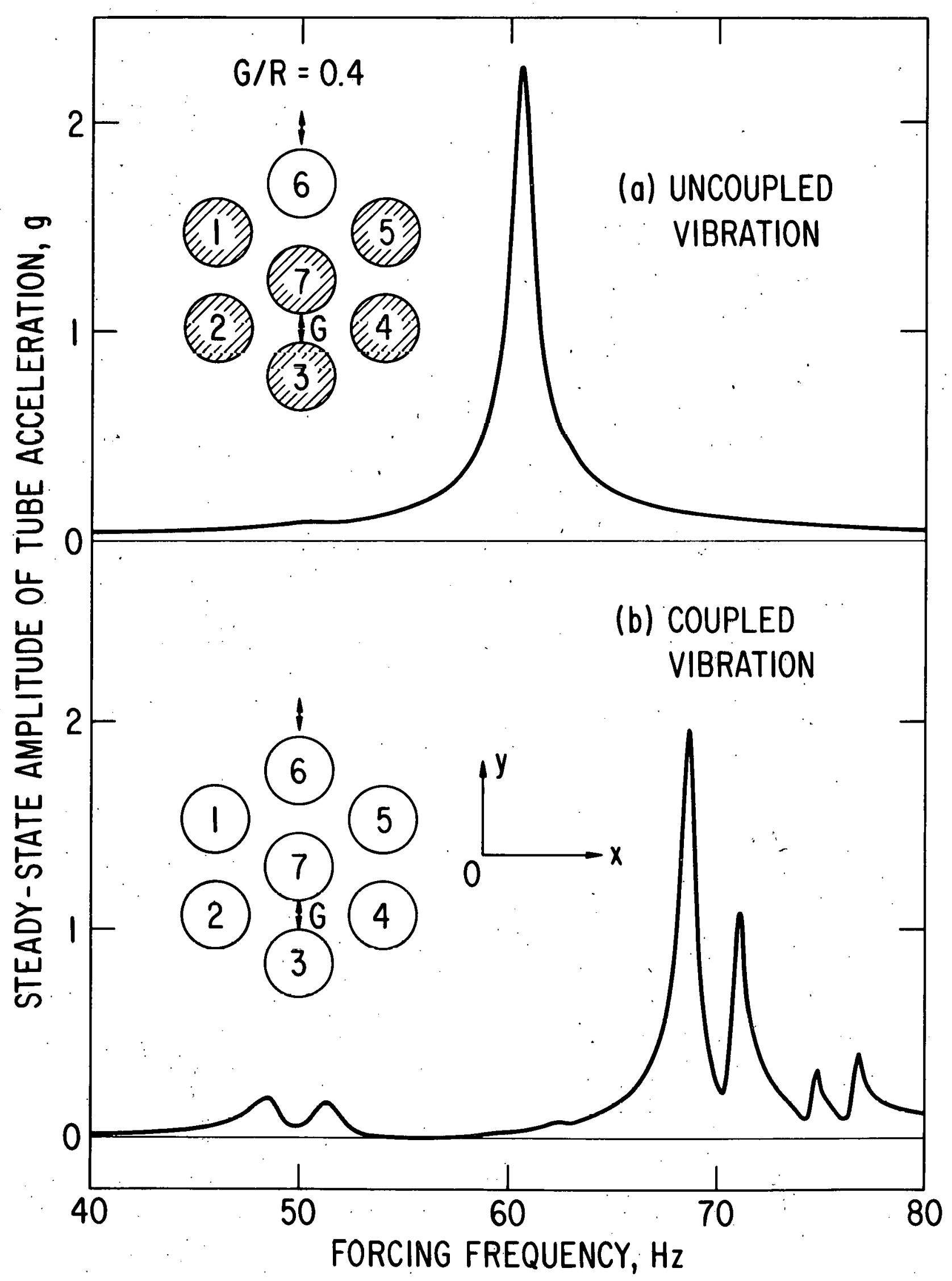

Fig. 19. Response of tube 6 in the y direction based on uncoupled and coupled vibrations for a 7 -tube array $(G / R=0.4)$ in water 


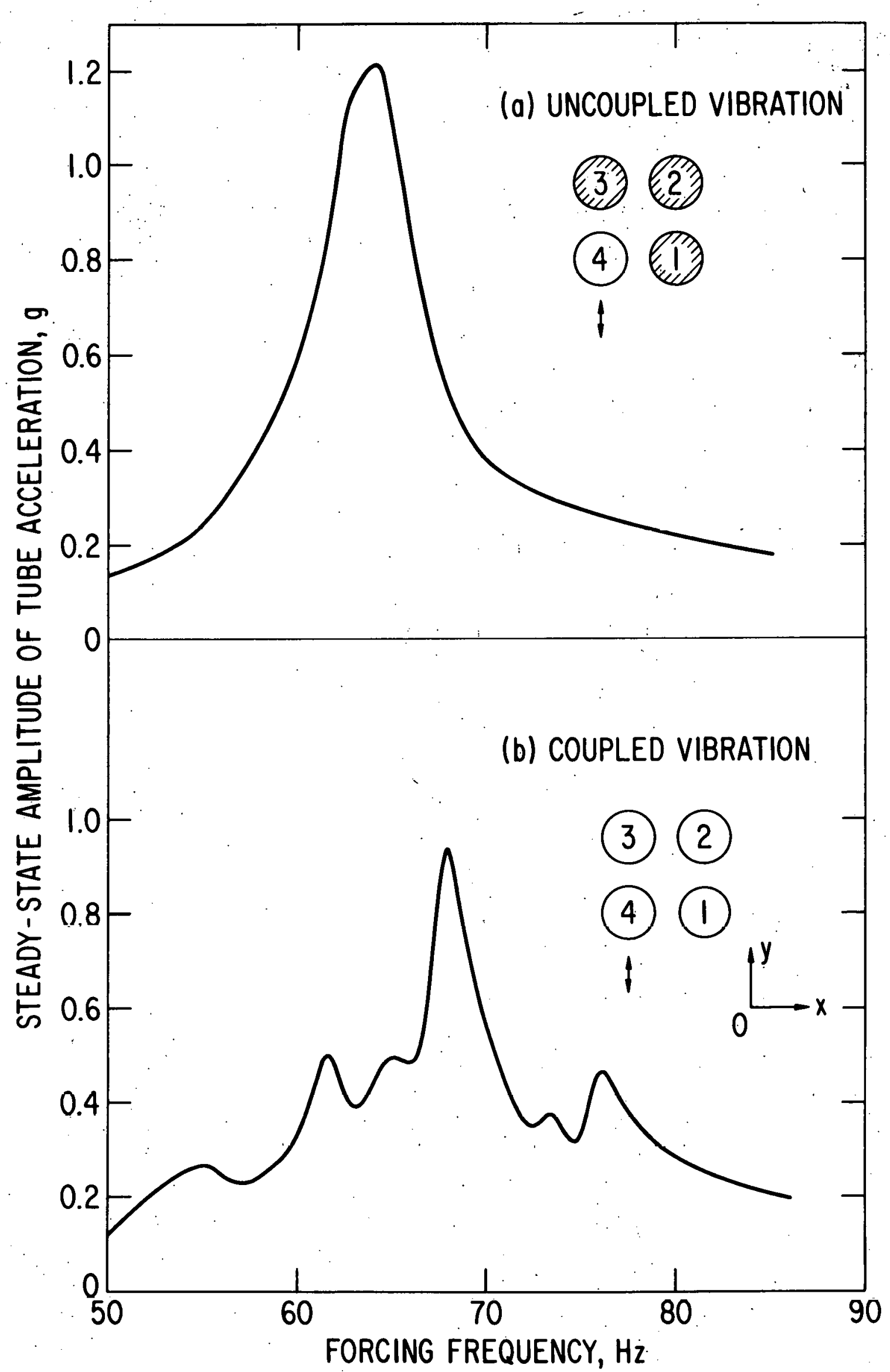

Fig. 20. Response of tube 4 in the y direction based on uncoupled and coupled vibrations for the 4-tube array in unconfined mineral oil 
Table 1. Experimental and analytical results for uncoupled vibration of a row of five tubes

\begin{tabular}{|c|c|c|c|c|c|c|c|c|}
\hline \multirow{2}{*}{$\begin{array}{l}\text { Gap-to } \\
\text { Radlus } \\
\text { Ratio } \\
\text { (G/R) }\end{array}$} & \multirow[t]{2}{*}{$\begin{array}{l}\text { Drection } \\
\text { of } \\
\text { Motion }\end{array}$} & \multirow[t]{2}{*}{$\begin{array}{c}\text { Tube } \\
\text { Number }\end{array}$} & \multirow{2}{*}{$\begin{array}{c}\text { Dimensionless } \\
\text { Spring } \\
\text { Constant } \\
\left(p_{1}\right) \\
\end{array}$} & \multicolumn{2}{|c|}{$\begin{array}{c}\text { Measured } \\
\text { Uncoupled Natural } \\
\text { Frequency, Hz }\end{array}$} & \multicolumn{2}{|c|}{$\begin{array}{c}\text { Measured } \\
\text { Damping } \\
\text { Ratto }\end{array}$} & \multirow{2}{*}{$\begin{array}{c}\text { Calculated } \\
\text { Uncoupled Natural } \\
\text { Frequency in } \\
\text { Water, } \mathrm{Hz}\end{array}$} \\
\hline & & & & In Air & In Water & In Air & In Water & \\
\hline \multirow{10}{*}{$\begin{array}{c}2.0 \\
(1.988)\end{array}$} & \multirow{5}{*}{$x$} & 1 & 104.3 & 83.79 & 69.63 & 0.00118 & 0.0044 & 70.07 \\
\hline & & 2 & 99.0 & 84.67 & 70.41 & 0.00095 & 0.0049 & 70.58 \\
\hline & & 3 & 128.5 & 84.27 & 69.92 & 0.00031 & 0.0053 & 70.39 \\
\hline & & 4 & 155.2 & $\cdot 84.38$ & 70.21 & 0.00028 & 0.0045 & 70.57 \\
\hline & & 5 & 354.0 & 77.93 & 65.50 & 0.00062 & 0.0043 & 66.87 \\
\hline & \multirow{5}{*}{8} & 1 & 129.0 & 84.08 & 70.02 & 0.00113 & 0.0042 & 70.31 \\
\hline & & 2 & 129.3 & 85.05 & 70.90 & 0.00032 & 0.0036 & 70.89 \\
\hline & & 3 & 242.6 & 84.86 & 70.51 & 0.00103 & 0.0044 & 70.86 \\
\hline & & 4 & 288.5 & 84.86 & 70.80 & 0.00078 & 0.0034 & 70.96 \\
\hline & & 5 & 354.0 & 77.93 & 66.70 & 0.00148 & 0.0042 & 66.87 \\
\hline \multirow{10}{*}{$\begin{array}{c}1.0 \\
(0.981)\end{array}$} & \multirow{5}{*}{$\mathbf{x}$} & 1 & 105.1 & 83.40 & 69.24 & 0.00044 & 0.0063 & 69.54 \\
\hline & & 2 & 84.2 & 83.79 & 68.75. & 0.00052 & 0.0078 & 69.39 \\
\hline & & 3 . & 98.3 & 83.69 & 68.85 & 0.00051 & 0.0088 & 69.43 \\
\hline & & 4 & 86.5 & 83.01 & 68.26 & 0.00063 & 0.0099 & 68.96 \\
\hline & & 5 & 186.6 & 77.05 & 64.94 & 0.00103 & 0.0047 & 65.93 \\
\hline & \multirow{5}{*}{$y$} & 1 & 155.8 & 83.89 & 69.92 & 0.00032 & 0.0037 & 69.91 \\
\hline & & 2 & 114.1 & 84.28 & 69.53 & 0.00054 & 0.0043 & 69.72 \\
\hline & & 3 & 254.9 & 84.28 & 69.63 & 0.00073 & 0.0044 & 69.82 \\
\hline & & 4 & 127.4 & 83.59 & 69.04 & 0.00152 & 0.0051 & 69.37 \\
\hline & & 5 & 253.4 & 77.25 & 65.53 & 0.00092 & 0.0039 & 66.07 \\
\hline \multirow{10}{*}{$\begin{array}{l}0.25 \\
0.248)\end{array}$} & \multirow{5}{*}{$\mathrm{x}$} & 1 & 99.2 & 83.40 & 68.55 & 0.00093 & 0.0073 & 68.45 \\
\hline & & 2 & 85.2 & 83.50 & 66.99 & 0.00045 & 0.0124 & 67.08 \\
\hline & & 3 & 92.0 & 83.50 & 67.29 & 0.00146 & 0.0137 & 67.23 \\
\hline & & 4 & 97.2 & 83.40 & 67.38 & 0.00131 & $0.0190^{\prime}$ & 67.28 \\
\hline & & 5 & 325.2 & 77.73 & 64.55 & 0.00108 & 0.0081 & 65.63 \\
\hline & \multirow{5}{*}{$y$} & 1 & 131.5 & 83.79 & 69.24 & 0.00046 & 0.0062 & 68.52 \\
\hline & & 2 & 101.1 & 83.79 & $67 . .38$ & 0.00055 & 0.0076 & 66.70 \\
\hline & & 3 & 97.2 & 83.59 & 66.80 & 0.00088 & 0.0070 & 66.53 \\
\hline & & 4 & 103.6 & 83.50 & .67 .19 & 0.00069 & 0.0076 & 66.75 \\
\hline & & 5 & . 930.5 & 78.02 & 65.42 & 0.00226 & 0.0046 & 65.66 \\
\hline
\end{tabular}


Table 2. Experimental and analytical results for uncoupled vibration of a group of three tubes

\begin{tabular}{|c|c|c|c|c|c|c|c|c|}
\hline \multirow{2}{*}{$\begin{array}{l}\text { Gap-to- } \\
\text { Radius } \\
\text { Ratio } \\
\text { (G/R) }\end{array}$} & \multirow[t]{2}{*}{$\begin{array}{l}\text { Direction } \\
\text { of } \\
\text { Motion }\end{array}$} & \multirow[t]{2}{*}{$\begin{array}{l}\text { Tube } \\
\text { Number }\end{array}$} & \multirow{2}{*}{$\begin{array}{c}\text { Dimensionless } \\
\text { Spring } \\
\text { Constant } \\
\left(p_{1}\right)\end{array}$} & \multicolumn{2}{|c|}{$\begin{array}{c}\text { Measured } \\
\text { Uncoupled Natural } \\
\text { Frequency, } \mathrm{Hz} \\
\end{array}$} & \multicolumn{2}{|c|}{$\begin{array}{c}\text { Measured } \\
\text { Damiping } \\
\text { Ratio }\end{array}$} & \multirow{2}{*}{$\begin{array}{l}\text { Calculated } \\
\text { Uncoupled Natural } \\
\text { Frequency in } \\
\text { Water, } \mathrm{Hz}\end{array}$} \\
\hline & & & & In Air & In Water & In Air & In Water & \\
\hline \multirow{6}{*}{$\begin{array}{c}2.0 \\
(1.933)\end{array}$} & \multirow{3}{*}{$\mathbf{x}$} & 1 & 53.2 & 82.03 & 68.35 & 0.00152 & 0.0038 & 68.53 \\
\hline & & 2 & 141.4 & 84.38 & 70.21 & 0.00090 & 0.0041 & 70.35 \\
\hline & & 3 & 386.0 & 77.24 & 65.82 & 0.00341 & 0.0041 & 66.22 \\
\hline & \multirow{3}{*}{$y$} & 1 & 55.2 & 82.13 & 68.55 & 0.00103 & 0.0037 & 68.59 \\
\hline & & 2 & 79.1 & 83.50 & 69.53 & 0.00095 & 0.0045 & 69.63 \\
\hline & & 3 & 123.2 & 76.46 & 65.33 & 0.00217 & 0.0034 & 65.55 \\
\hline \multirow{6}{*}{$\begin{array}{c}1.0 \\
(0.983)\end{array}$} & \multirow{3}{*}{$x$} & 1 & 62.6 & 82.23 & 69.26 & 0.00072 & 0.0047 & 68.28 \\
\hline & & 2 & 79.5 & 83.50 & 69.14 & 0.00109 & 0.0087 & 69.08 \\
\hline & & 3 & 115.8 & 76.76 & 65.04 & 0.00073 & 0.0071 & 65.36 \\
\hline & \multirow{3}{*}{$y$} & 1 & 71.1 & 82.52 & 68.36 & 0.00095 & 0.0042 & 68.37 \\
\hline & & 2 & 63.4 & 83.01 & 68.55 & 0.00174 & 0.0075 & 68.75 \\
\hline & & 3 & 77.4 & 76.17 & 64.55 & 0.00215 & 0.0063 & 64.91 \\
\hline \multirow{6}{*}{$\begin{array}{c}0.5 \\
(0.475)\end{array}$} & \multirow{3}{*}{$\mathbf{x}$} & 1 & 58.5 & 82.42 & 67.58 & 0.00076 & 0.0044 & 67.62 \\
\hline & & 2 & 94.0 & 83.98 & 67.68 & 0.00183 & 0.0051 & 68.26 \\
\hline & & 3 & 82.9 & 76.07 & 63.09 & 0.00226 & 0.0052 & 63.76 \\
\hline & \multirow{3}{*}{$y$} & 1 & .52 .6 & 82.13 & 66.99 & 0.00125 & 0.0048 & 66.75 \\
\hline & & 2 & 59.2 & 83.0 .1 & 67.77 & 0.00233 & 0.0053 & 67.79 \\
\hline & & 3 & 88.3 & 76.17 & 63.87 & 0.00119 & 0.0055 & 64.12 \\
\hline
\end{tabular}


Table 3. Experimencal and anilycical results for uncoupled vibration of a group of ocven tubes

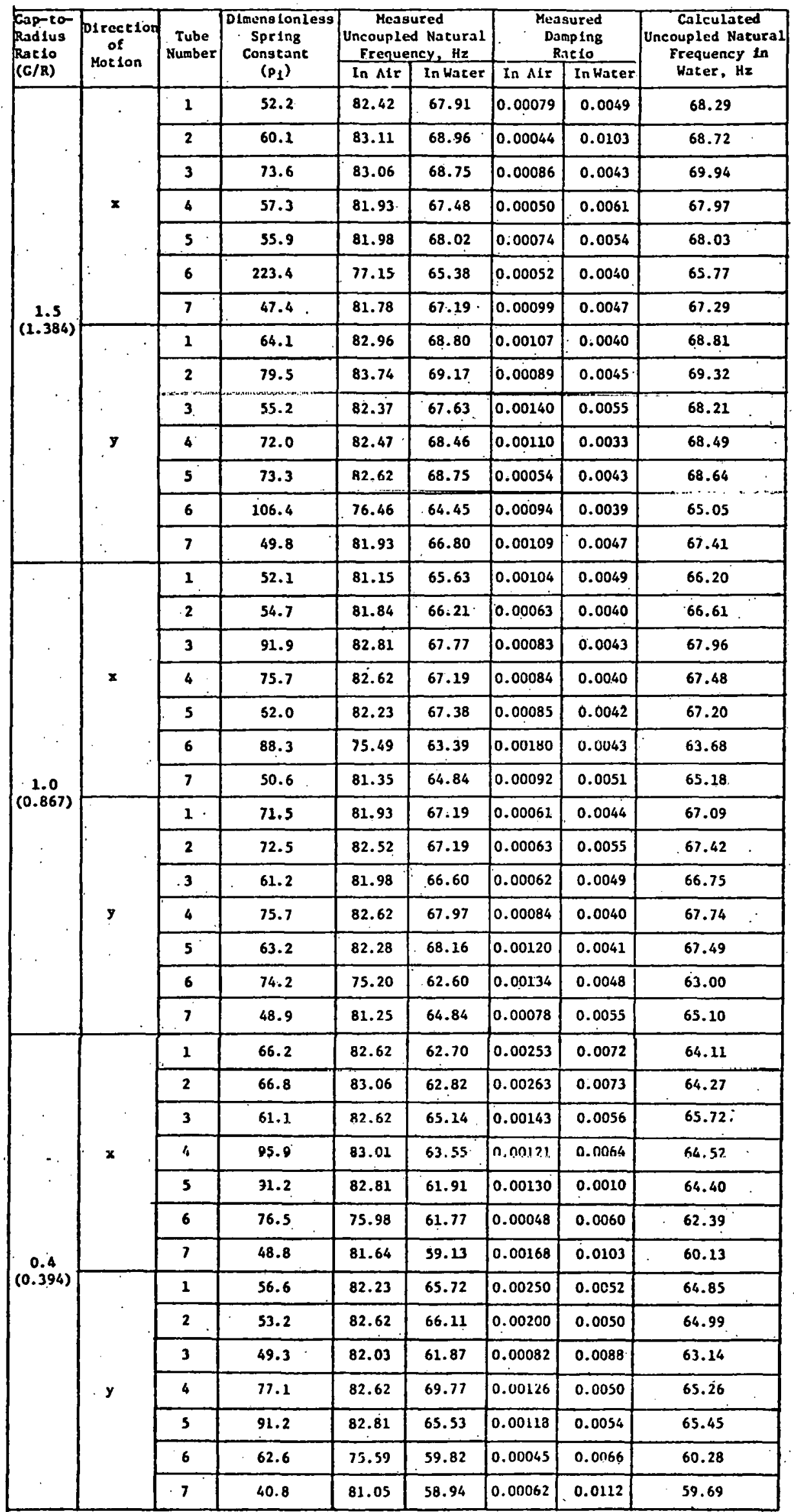


Table 4. Experimental and analytical results for uncoupled vibration of the four-tube array in unconfined water

\begin{tabular}{|c|c|c|c|c|c|c|c|c|}
\hline \multirow{2}{*}{$\begin{array}{l}\text { Gap-to- } \\
\text { Radius } \\
\text { Ratio } \\
\text { (G/R) }\end{array}$} & \multirow[t]{2}{*}{$\begin{array}{l}\text { Direction } \\
\quad \text { of } \\
\text { Motion }\end{array}$} & \multirow[t]{2}{*}{$\begin{array}{c}\text { Tube } \\
\text { Number }\end{array}$} & \multirow{2}{*}{$\begin{array}{c}\text { Dimensionless } \\
\text { Spring } \\
\text { Constant } \\
\left(p_{1}\right)\end{array}$} & \multicolumn{2}{|c|}{$\begin{array}{c}\text { Measured } \\
\text { Uncoupled Natural } \\
\text { Frequency, } \mathrm{Hz}\end{array}$} & \multicolumn{2}{|c|}{$\begin{array}{l}\text { Measured } \\
\text { Damping } \\
\text { Ratio }\end{array}$} & \multirow{2}{*}{$\begin{array}{c}\text { Calculated } \\
\text { Uncoupled Natural } \\
\text { Frequency in } \\
\text { Water, } \mathrm{Hz}\end{array}$} \\
\hline & & & & In Air & In Water & In Air & In Water & \\
\hline \multirow{8}{*}{$\begin{array}{c}0.5 \\
(0.585)\end{array}$} & \multirow{4}{*}{$\mathbf{x}$} & 1 & .98 .1 & 83.79 & 68.65 & 0.00099 & 0.0079 & 68.57 \\
\hline & & 2 & 60.6 & 83.98 & 68.85 & 0.00169 & 0.0138 & 68.42 \\
\hline & & 3 & 78.1 & 83.59 & 68.55 & 0.00566 & 0.0125 & 68.41 \\
\hline & & 4 & 1030.0 & 77.83 & 65.33 & 0.00091 & 0.0080 & 65.55 \\
\hline & \multirow{4}{*}{$\mathrm{y}$} & 1 & 75.0 & 83.30 & 67.77 & 0.00131 & 0.0072 & 68.17 \\
\hline & & 2 & 74.9 & 84.28 & 68.95 & 0.00286 & 0.0147 & 68.82 \\
\hline & & 3 & 86.4 & 83.78 & 68.46 & 0.00290 & 0.0089 & 68.57 \\
\hline & & 4 & 228.1 & 77.34 & 64.16 & 0.00633 & 0.0117 & 65.13 \\
\hline
\end{tabular}


Table 5. Experimental and analytical results for uncoupled vibration of the four-tube array near a flat wall

\begin{tabular}{|c|c|c|c|c|c|}
\hline $\begin{array}{l}\text { Gap-to- } \\
\text { Radius } \\
\text { Ratio } \\
\left(G_{W} / R\right)\end{array}$ & $\begin{array}{l}\text { Direction } \\
\text { of } \\
\text { Motion }\end{array}$ & $\begin{array}{c}\text { Tube } \\
\text { Number }\end{array}$ & $\begin{array}{c}\text { Measured } \\
\text { Uncoupled Natural } \\
\text { Frequency, } \mathrm{Hz}\end{array}$ & $\begin{array}{l}\text { Measured } \\
\text { Damping } \\
\text { Ratio }\end{array}$ & $\begin{array}{c}\text { Calculated } \\
\text { Uncoupled Natural } \\
\text { Frequency, } \mathrm{Hz}\end{array}$ \\
\hline \multirow{8}{*}{1.0} & \multirow{4}{*}{$x$} & 1 & 68.46 & 0.0066 & 68.27 \\
\hline & & 2 & 67.24 & 0.0071 & 66.87 \\
\hline & & 3 & 66.75 & 0.0059 & 66.88 \\
\hline & & 4 & 65.14 & 0.0101 & 65.29 \\
\hline & \multirow{4}{*}{$y$} & 1 & 67.58 & 0.0078 & 67.93 \\
\hline & & 2 & 67.04 & 0.0065 & 67.38 \\
\hline & & 3 & 66.55 . & 0.0087 & 67.15 \\
\hline & & 4 & 64.06 & 0.0070 & 64.93 \\
\hline \multirow{8}{*}{0.5} & \multirow{4}{*}{$\mathbf{x}$} & 1 & 68.51 & 0.0059 & 68.14 \\
\hline & & 2 & 65.53 & 0.0138 & 65.31 \\
\hline & & 3 & 65.38 & 0.0143 & 65.31 \\
\hline & & 4 & 65.19 & 0.0094 & 65.18 \\
\hline & \multirow{4}{*}{$y$} & 1 & 67.48 & 0.0038 & 67.85 \\
\hline & & 2 & 66.16 & 0.0087 & 66.15 \\
\hline & & 3 & 66.06 & 0.0096 & 65.91 \\
\hline & & 4 & 64.21 & 0.0103 & 64.86 \\
\hline
\end{tabular}


Table 6. Experimental and analytical results for uncoupled vibration of the four-tube array contalned in a cylinder

\begin{tabular}{|c|c|c|c|c|c|c|}
\hline $\begin{array}{l}\text { Radius } \\
\text { Rat10 } \\
R_{e} / 8\end{array}$ & $\begin{array}{c}\text { Eccentricity } \\
G_{\mathrm{e}} / \mathrm{R}\end{array}$ & $\begin{array}{c}\text { Direction } \\
\text { of } \\
\text { Motion }\end{array}$ & \begin{tabular}{|c|} 
Tube \\
Number
\end{tabular} & \begin{tabular}{|c|} 
Measured \\
Uncoupled \\
Natural \\
Frequency, $\mathrm{Hz}$
\end{tabular} & \begin{tabular}{|l|} 
Measured \\
Damping \\
Rat1o
\end{tabular} & $\begin{array}{c}\text { Calculated } \\
\text { Uncoupled } \\
\text { Natural } \\
\text { Frequency, Hz }\end{array}$ \\
\hline \multirow{24}{*}{4.0} & \multirow{8}{*}{0.0} & \multirow{4}{*}{$x$} & 1 & 65.33 & 0.0095 & 66.07 \\
\hline & & & 2 & 65.77 & 0.0082 & 65.89 \\
\hline & & & 3 & 65.92 & 0.0071 & 65.91 \\
\hline & & & 4 & 62.26 & 0.0055 & 63.43 \\
\hline & & \multirow{4}{*}{$\mathbf{y}$} & 1 & 64.70 & 0.0079 & 65.68 \\
\hline & & & 2 & 65.53 & 0.0073 & 66.28 \\
\hline & & & 3 & 65.87 & 0.0068 & 66.06 \\
\hline & & & 4 & 62.26 & 0.0053 & 63.02 \\
\hline & \multirow{8}{*}{0.4} & \multirow{4}{*}{$x$} & 1 & 65.48 & 0.0060 & 65.47 \\
\hline & & & 2 & 65.14 & 0.0070 & 66.19 \\
\hline & & & 3 & 65.38 & 0.0068 & 66.21 \\
\hline & & & 4 & 62.60 & 0.0054 & 62.92 \\
\hline & & \multirow{4}{*}{$y$} & 1 & 64.94 & 0.0069 & 65.07 \\
\hline & & & 2 & 65.33 & 0.0060 & 66.62 \\
\hline & & & 3 & 64.84 & 0.0106 & 66.40 \\
\hline & & & 4 & 62.55 & 0.0054 & 62.50 \\
\hline & \multirow{8}{*}{0.8} & \multirow{4}{*}{$x$} & 1 & 65.33 & 0.0069 & 64.25 \\
\hline & & & 2 & 62.84 & 0.0093 & 66.30 \\
\hline & & & 3 & 63.82 & 0.0082 & 66.31 \\
\hline & & & 4 & 62.79 & 0.0074 & 61.87 \\
\hline & & \multirow{4}{*}{$\boldsymbol{P}$} & 1 & 65.82 & 0.0057 & 63.89 \\
\hline & & & 2 & 64.21 & 0.0091 & 66.79 \\
\hline & & & 3 & 62.94 & 0.0111 & 65.57 \\
\hline & & & 4 & 62.45 & 0.0075 & 61.49 \\
\hline \multirow{16}{*}{3.5} & \multirow{8}{*}{0.0} & \multirow{4}{*}{$x$} & 1 & 63.67 & 0.0079 & 64.43 \\
\hline & & & 2 & 64.31 & 0.0092 & 64.25 \\
\hline & & & 3 & 64.75 & 0.0094 & 64.27 \\
\hline & & & 4 & $60: 84$ & 0.0105 & 62.02 \\
\hline & & \multirow{4}{*}{$y$} & 1 & 62.21 & 0.0101 & 64.05 \\
\hline & & & 2 & 64.50 & 0.0091 & 64.63 \\
\hline & & & 3 & 63.82 & 0.0100 & 64.42 \\
\hline & & & 4 & 59.91 & 0.0202 . & 61.62 \\
\hline & \multirow{8}{*}{0.4} & \multirow{4}{*}{$x^{\prime}$} & 1 & 64.65 & 0.0069 & 62.73 \\
\hline & & & 2 & 63.67 & 0.0085 & 64.94 \\
\hline & & & 3 & 63.92 & 0.0070 & 64.96 \\
\hline & & & 4 & 61.13 & 0.0128 & 60.56 \\
\hline & & \multirow{4}{*}{$y$} & 1 & 63.78 & 0.0085 & 62.36 \\
\hline & & & 2 & 62.45 & $0.0073 \ldots$ & $65.40 \ldots$ \\
\hline & & & 3 & 63.92 & 0.0090 & 65.19 \\
\hline & & & 4 & 61.67 & 0.0067 & 60.17 \\
\hline
\end{tabular}


42

Table 7. Experimentai and analytical results for coupled vibration of 5 tubes

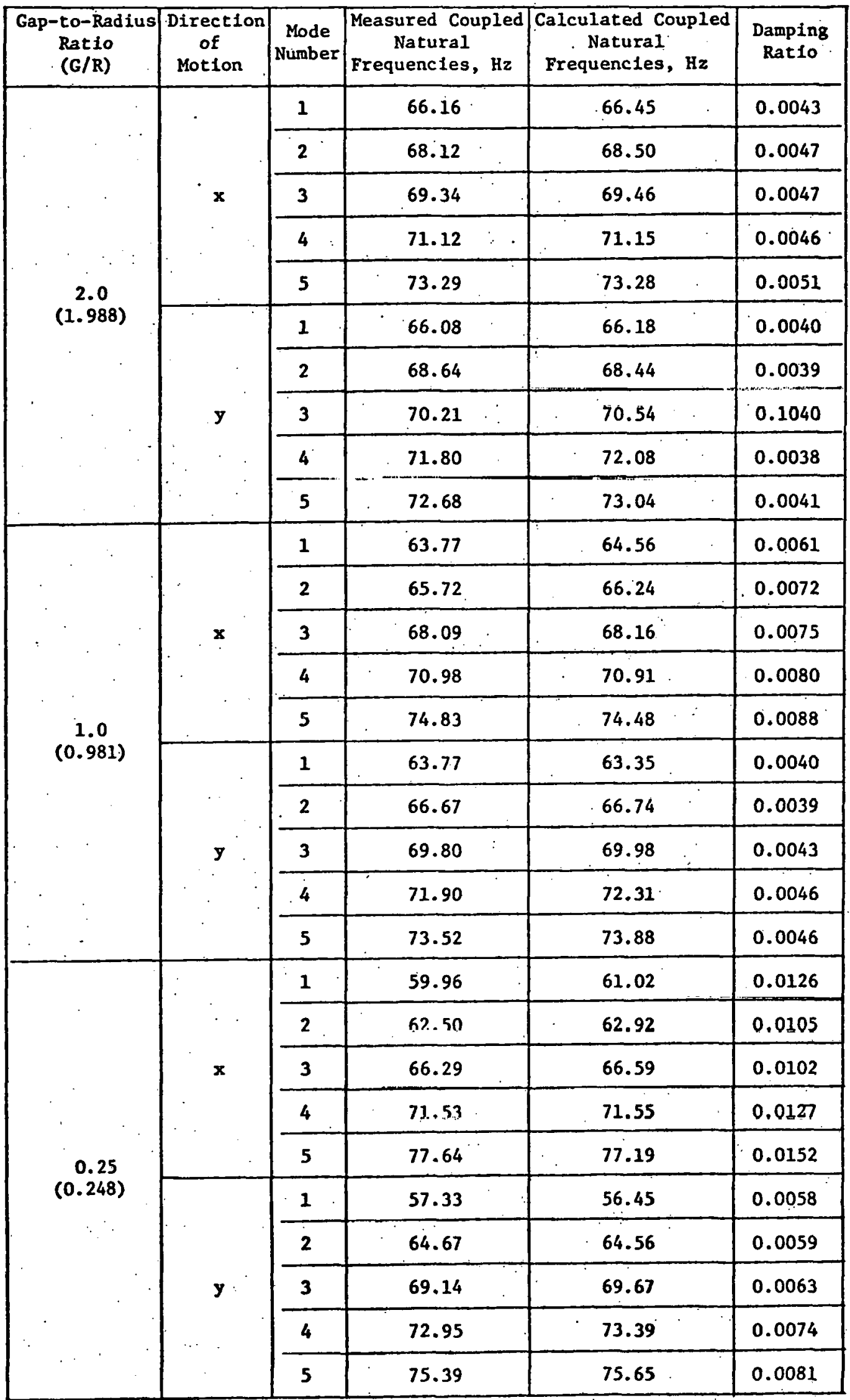


Table 8. Experimental and analytical results for coupled vibration of 3 tubes

\begin{tabular}{|c|c|c|c|c|}
\hline \begin{tabular}{|l|} 
Gap-to- \\
Radius \\
Ratio \\
(G/R) \\
\end{tabular} & $\begin{array}{c}\text { Mode } \\
\text { Number }\end{array}$ & $\begin{array}{c}\text { Measured Coupled } \\
\text { Natural } \\
\text { Frequencies, } \mathrm{Hz}\end{array}$ & $\begin{array}{c}\text { Cálculated Coupled } \\
\text { Natural } \\
\text { Frequencies, Hz }\end{array}$ & $\begin{array}{l}\text { Damping } \\
\text { Ratio }\end{array}$ \\
\hline \multirow{6}{*}{$\begin{array}{c}2.0 \\
(1.933)\end{array}$} & 1 & 64.02 & 64.61 & 0.0036 \\
\hline & 2 & 65.20 & $65.23^{\circ}$ & 0.0038 \\
\hline & 3 & 67.65 & 67.76 & 0.0039 \\
\hline & 4 & 69.04 & 69.10 & 0.0039 \\
\hline & 5 & 71.28 & 71.10 & 0.0043 \\
\hline & 6 & 71.52 & 71.61 & 0.0042 \\
\hline \multirow{6}{*}{$\begin{array}{c}1.0 \\
(0.983)\end{array}$} & 1 & 61.21 & 62.04 & 0.0061 \\
\hline & 2 & 64.02 & 63.84 & 0.0063 \\
\hline & 3 & 66.25 & 66.42. & 0.0060 \\
\hline & 4 & 69.52 & 69.68 & 0.0065 \\
\hline & 5 & 72.10 & 71.78 & 0.0069 \\
\hline & 6 & 72.85 & 72.72 & 0.0070 \\
\hline \multirow{6}{*}{$\begin{array}{c}0.5 \\
(0.475)\end{array}$} & 1 . & 57.42 & 58.15 & 0.0046 \\
\hline & 2 & 62.29 & 62.32 & 0.0051 \\
\hline & 3 & 64.76 & 64.86 & 0.0047 \\
\hline & 4 & 70.24 & 70.14 & 0.0055 \\
\hline & 5 & 72.88 & 72.66 & 0.0054 \\
\hline & 6 & 74.47 & 74.32 & 0.0055 \\
\hline
\end{tabular}


44

Table 9. Experimental and analytical resulto for coupled vibration of 7 cubca

\begin{tabular}{|c|c|c|c|c|}
\hline $\begin{array}{l}\text { Gap-to- } \\
\text { Radlus } \\
\text { Ratlo } \\
(G / 8) \\
\end{array}$ & $\begin{array}{c}\text { Mode } \\
\text { Number }\end{array}$ & $\begin{array}{c}\text { Measured } \\
\text { Nacural } \\
\text { Frequencles, } \mathrm{Hz}\end{array}$ & $\begin{array}{c}\text { Calculated } \\
\text { Natural } \\
\text { Frequencles, Hz }\end{array}$ & $\begin{array}{c}\text { Calculated } \\
\text { Dumping } \\
\text { Rat 10 }\end{array}$ \\
\hline \multirow{14}{*}{$\begin{array}{c}1.5 \\
(1.384)\end{array}$} & 1 & 60.25 & 61.18 & 0.0043 \\
\hline & 2 & 61.91 & 62.66 & 0.0045 \\
\hline & 3 & 62.70 & 62.76 & 0.0052 \\
\hline & 4 & 64.65 & 64.74 & 0.0040 \\
\hline & 5 & 66.06 . & 66.33 & 0.0045 \\
\hline & 6. & 66.46 & 66.94 & 0.0048 \\
\hline & 7 & 67.53 & 68.31 & 0.0043 \\
\hline & 8 & 68.99 & 68.79 & 0.0055 \\
\hline & 9 & 69.87 & 70.22 & 0.0051 \\
\hline & 10 & 70.75 & 71.07 & 0.0060 \\
\hline & 11. & 71.58 & 72.03 & 0.0066 \\
\hline & 12 & 72.41 & 73.13 & 0.0050 \\
\hline & 13 & 73.44 & 73.32 & 0.0056 \\
\hline & 14 & 74.36 & 74.47 & 0.0049 \\
\hline \multirow{14}{*}{$\begin{array}{c}1.0 \\
(0.867)\end{array}$} & 1 & 55.61 & 56.87 & 0.0041 \\
\hline & 2 & 58.20 & 58.73 & 0.0044 \\
\hline & 3 & 58.89 & 58.86 & 0.0042 \\
\hline & 4 & 62.06 & 62.12 & 0.0041 \\
\hline & 5 & 64.45 & 64.43 & 0.0043 \\
\hline & 6 & 65.33 & 64.99 & 0.0042 \\
\hline & 7 & 68.36 & 67.68 & 0.0050 \\
\hline & 8 & 69.29 & 68.23 & 0.0044 \\
\hline & 9 & 70.85 & 70.12 & 0.0049 \\
\hline & 10 & 71.63 & 71.26 & 0.0047 \\
\hline & 11 & 72.66 & 72.69 & 0.0048 \\
\hline & 12 & 74.07 & 74.04 & 0.0052 \\
\hline & 13 & 74.46 & 74.27 & 0.0056 \\
\hline & 18 & 75.54 & $75: 79$ & 0.0050 \\
\hline \multirow{14}{*}{$\begin{array}{c}0.4 \\
(0.394)\end{array}$} & 1 & 48.39 & 49.69 & 0.0048 \\
\hline & 2 & 50.96 & .51 .35 & 0.0077 \\
\hline & 3 & 51.41 & 51.70 & 0.0066 \\
\hline & 4 & 59.47 & 39.10 & ก. กกร7. \\
\hline & 5 & 60.99 & 61.35 & 0.0054 \\
\hline & 6 & 62.40 & 62.09 & 0.0050 \\
\hline & 7 & 68.41 & 67.99 & 0.0067 \\
\hline & 8 & 69.14 & 68.30 & 0.0057 \\
\hline & 9 & 70.80 & 70.74 & 0.0074 \\
\hline & 10 & 72.46 & 72.09 & 0.0062 \\
\hline & 11 & 74.46 & 74.22 & 0.0079 \\
\hline & 12 & 76.07 & 76.02 & 0.0094 \\
\hline & 13 & 76.46 & 76.09 & 0.0099 \\
\hline & 14 & 78.56 & 78.28 & 0.0065 \\
\hline
\end{tabular}


Table 10. Experimental and analytical results for coupled vibration of the four-tube array in unconfined water

\begin{tabular}{|c|c|c|c|c|}
\hline $\begin{array}{l}\text { Gap-to- } \\
\text { Radius } \\
\text { Ratio } \\
(\text { G/R })\end{array}$ & $\begin{array}{c}\text { Mode } \\
\text { Number }\end{array}$ & $\begin{array}{c}\text { Measured Coupled } \\
\text { Natural } \\
\text { Frequencles, Hz }\end{array}$ & $\begin{array}{c}\text { Calculated Coupled } \\
\text { Natural } \\
\text { Frequencies, Hz }\end{array}$ & $\begin{array}{c}\text { Damping } \\
\text { Ratio }\end{array}$ \\
\hline 1 & 56.79 & 57.90 & 0.0090 \\
\hline 0.5 & 62.79 & 62.99 & 0.0094 \\
\hline$(0.585)$ & 5 & 66.26 & 66.73 & 0.0123 \\
\hline & 6 & 69.53 & 67.87 & 0.0091 \\
\hline & 7 & 71.88 & 71.38 & 0.0117 \\
\hline & 7 & 76.32 & 74.19 & 0.0124 \\
\hline
\end{tabular}


Table 11. Experimental and Analytical Results for Coupled Vibration of the Four-Tube Array Near a Flat Wall

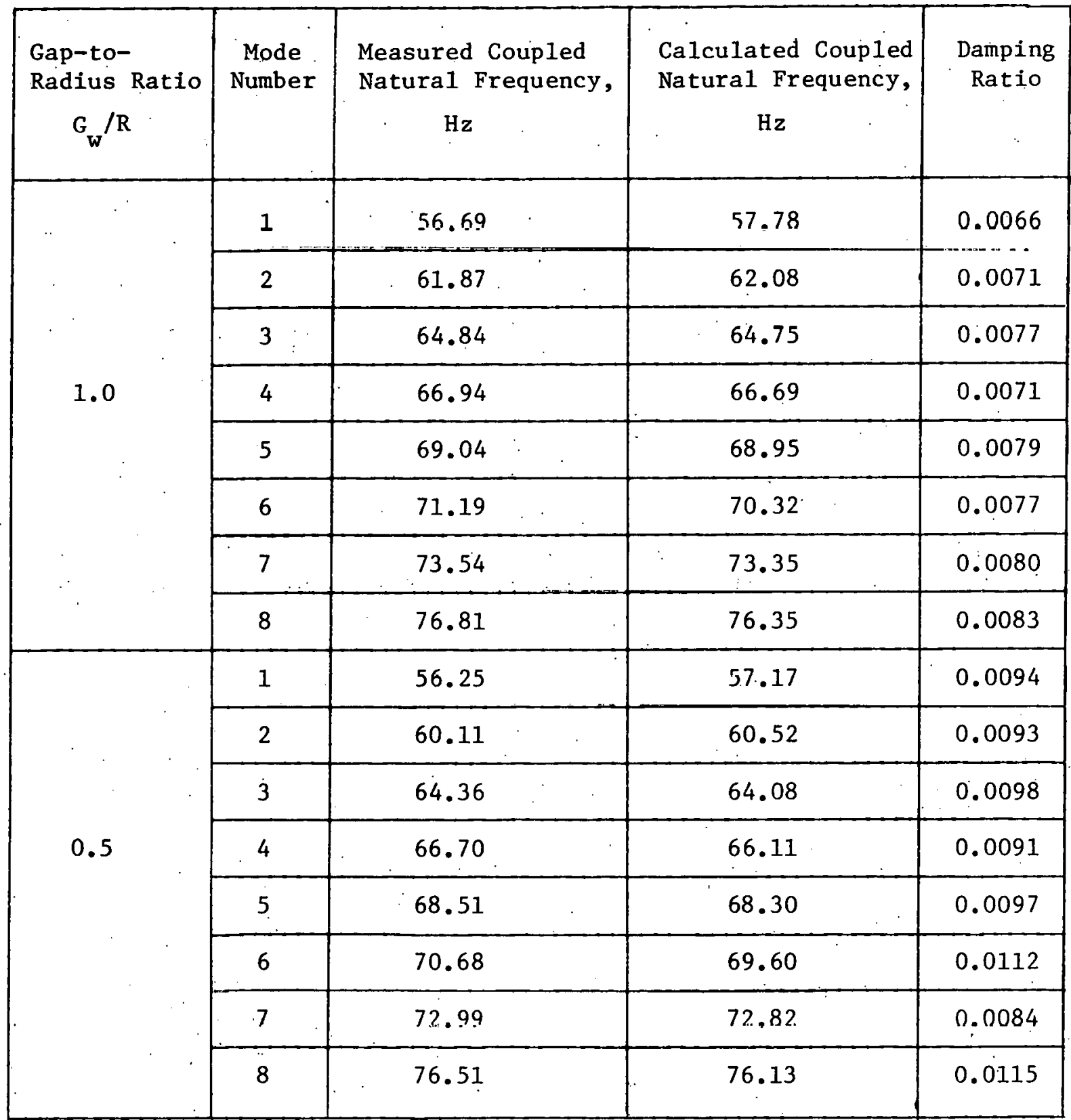


Table 12. Experimental and Analytical Results for Coupled Vibration of the Four-Tube Axray Contained in a Cylinder

\begin{tabular}{|c|c|c|c|c|c|}
\hline $\begin{array}{l}\text { Radius } \\
\text { Rat1o } \\
\text { R/R }\end{array}$ & $\begin{array}{c}\text { Eccentriclty } \\
\text { G/R }\end{array}$ & $\begin{array}{l}\text { Yode } \\
\text { Number }\end{array}$ & $\begin{array}{l}\text { Measured Coupled } \\
\text { Natural Frequency, } \\
\text { He }\end{array}$ & $\begin{array}{c}\text { Calculated Coupled } \\
\text { Natural Frequency, } \\
\text { Hz }\end{array}$ & $\begin{array}{l}\text { Damp Ing } \\
\text { Rat1o }\end{array}$ \\
\hline \multirow{24}{*}{4.0} & \multirow{8}{*}{0.0} & 1 & 56.15 & 57.86 & 0.0061 \\
\hline & & 2. & 59.52 & 59.98 & 0.0058 \\
\hline & & 3 & 62.21 & 62.11 & 0.0074 \\
\hline & & 4 & 62.25 & 62.37 & 0.0070 \\
\hline & & 5 & 67.53 & 68.31 & 0.0070 \\
\hline & & 6 & 69.43 & 69.27 & 0.0080 \\
\hline & & 7 & 72.27 & 72.22 & .0 .0083 \\
\hline & & 8 & 76.66 & 76.43 & 0.0086 \\
\hline & \multirow{8}{*}{0.4} & 1 & 56.25 & 57.81 & 0.0058 \\
\hline & & 2 & 59.40 & .59 .12 & 0.0054 \\
\hline & & 3 & 61.67 & 61.96 & 0.0062 \\
\hline & & 4 & 62.26 & 62.80 & 0.0075 \\
\hline & & 5 & 67.68 & 68.06 & 0.0066 \\
\hline & & 6 & 69.43 & 69.15 & 0.0073 \\
\hline & & 7 & 72.11 & 72.34 & 0.0079 \\
\hline & & 8 & 76.61 & 76.43 & 0.0081 \\
\hline & \multirow{8}{*}{0.8} & 1 & 55.86 & 57.29 & 0.0064 \\
\hline & & 2 & 58.11 & 57.63 & 0.0071 \\
\hline & & 3 & 60.74 & .61 .25 & $.0: 0075$ \\
\hline & & 4 & $62.65^{\circ}$ & 63.14 & 0.0092 \\
\hline & & 5 & 67.29 & 67.33 & 0.0076 \\
\hline & & 6 & 68.60 & 68.79 & 0.0084 \\
\hline & & 7 & 71.53 & 72.34 & 0.0100 \\
\hline & & 8 & 76.32 & 76.35 & 0.0099 \\
\hline \multirow{16}{*}{$\begin{array}{l}\because \cdot \\
3.5\end{array}$} & \multirow{8}{*}{0.0} & 1 & 55.57 & 57.43 & 0.0091 \\
\hline & & 2. & 57.03 & 57.70 & 0.0090 \\
\hline & & 3 & 59.33 & 59.56 & 0.0085 \\
\hline & & 4 & 59.77 & 59.83 & 0.0087 \\
\hline & & 5 & 66.31 & 67.40 . & 0.0105 \\
\hline & & 6 & 68.07 & 68.25 . & 0.0100 \\
\hline & & 7 & 70.90 & $70.59^{\circ}$ & 0.0102 \\
\hline & & 8 & 76.22 & 76.18 & 0.0113 \\
\hline & \multirow{8}{*}{0.4} & 1 & 55.76 & 55.33 & 0.0076 \\
\hline & & 2 & 57.37 & 57.23 & 0.0084 \\
\hline & & 3 & 59.20 & 59.03 & 0.0078 \\
\hline & & 4 & 59.72 & 60.87 & 0.0076 \\
\hline & & 5 & 66.70 & 66.42 & 0.0088 \\
\hline & & 6 & 68.21 & 67.91 & 0.0087 \\
\hline & & 7 & 70.31 & 70.99 & 0.0089 \\
\hline & & 8 . & 76.17 & 76.12 & 0.0099 \\
\hline
\end{tabular}


Table 13. Expe:imental and Analytical Results for Coupled Vibrations of the Four-Tube Array Partially Submerged in Water

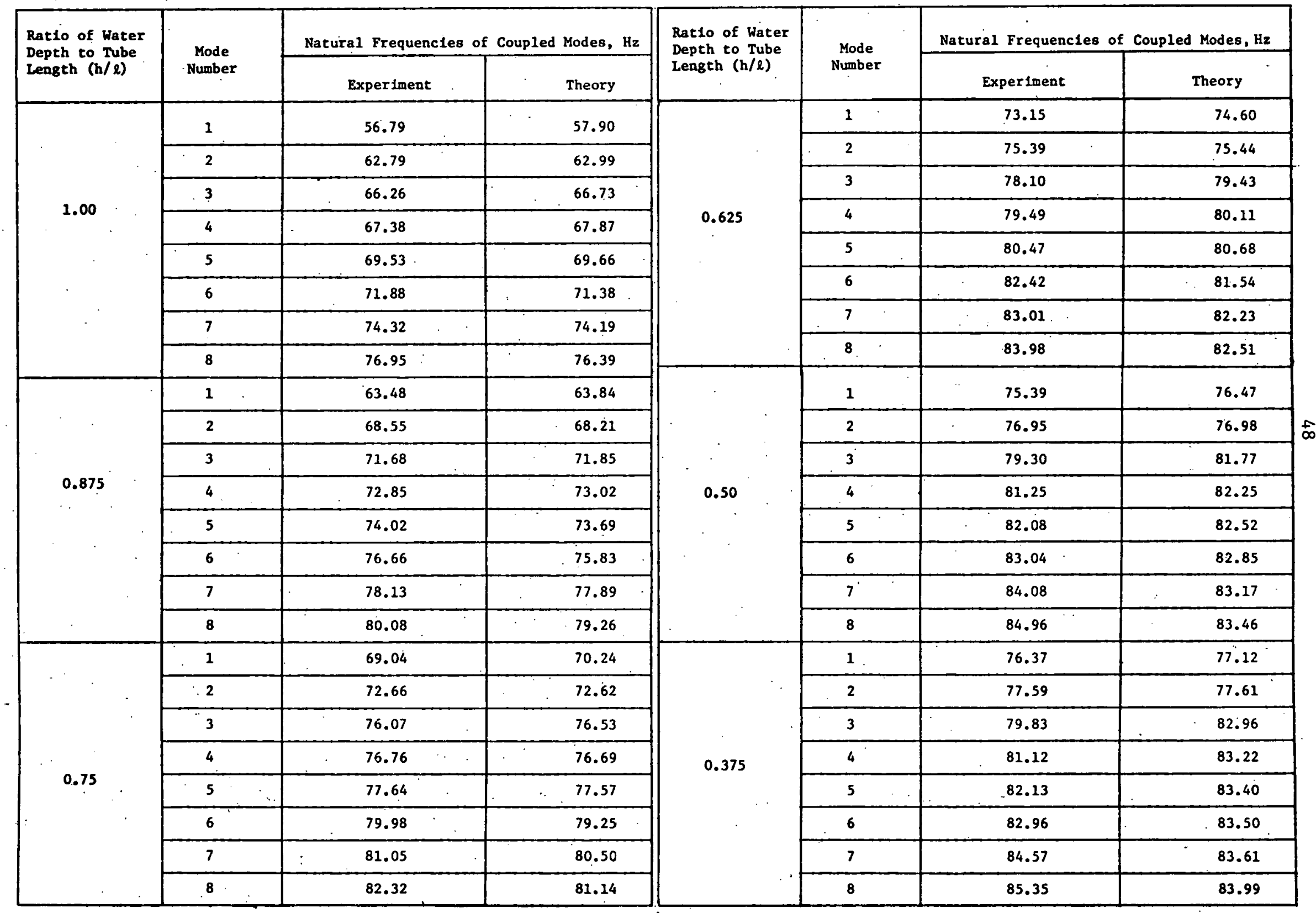


Table 14. Experimental Results for Uncoupled Vibration of the Four-Tube Arrays in Viscous Fluids

\begin{tabular}{|c|c|c|c|c|c|c|}
\hline \multirow{2}{*}{ Conditions } & \multirow{2}{*}{$\begin{array}{l}\text { Direction } \\
\text { of } \\
\text { Motion }\end{array}$} & \multirow{2}{*}{$\begin{array}{l}\text { Tube } \\
\text { Number }\end{array}$} & \multicolumn{2}{|c|}{$\begin{array}{l}\text { Measured Uncoupled } \\
\text { Natural. Frequency, Hz }\end{array}$} & \multicolumn{2}{|c|}{$\begin{array}{l}\text { Measured Damping } \\
\text { Ratio }\end{array}$} \\
\hline & & & Water & Mineral Oil & Water & Mineral oil \\
\hline \multirow{8}{*}{$\begin{array}{l}\text { In unconfined } \\
\text { fluid }\end{array}$} & \multirow{4}{*}{$\mathbf{x}$} & 1. & 68.65 & 68.31 & 0.0079 & 0.0262 \\
\hline & & 2 & 68.85 & 69.14 & 0.0138 & 0.0318 \\
\hline & & 3 & 68.55 & 68.41 & 0.0125 & 0.0285 \\
\hline & & 4 & 65.33 & 65.04 & 0.0080 & 0.0309 \\
\hline & \multirow{4}{*}{$y$} & 1 & 67.77 & 67.48 & $0.0072^{\circ}$ & 0.0284 \\
\hline & & 2 & 68.95 & 69.14 & 0.0147 & 0.0336 \\
\hline & & 3 & 68.46 & 68.56 & 0.0089 & 0.0285 \\
\hline & & 4 & 64.16 & 64.99 & 0.0117 & 0.0290 \\
\hline \multirow{8}{*}{$\begin{array}{c}\text { Near a } \\
\text { flat wall } \\
\left(G_{w} / R=0.5\right)\end{array}$} & \multirow{4}{*}{$x$} & 1 & 68.51 & 68.56 & 0.0059 & 0.0254 \\
\hline & & 2 & 65.53 & 66.31 & 0.0138 & 0.0311 \\
\hline & & 3 & 65.38 & 65.58 & 0.0143 & 0.0308 \\
\hline & & 4 & 65.19 & 64.70 & 0.0094 & 0.0375 \\
\hline & \multirow{4}{*}{$y$} & 1 & 67.48 & 67.48 & 0.0038 & 0.0350 \\
\hline & & 2 & 66.16 & 65.82 & 0.0087 & 0.0268 \\
\hline & & 3 & 66.06 & 66.02 & 0.0006 & 0.0323 \\
\hline & & 4 & 64.21 & 64.84 & 0.0103 & 0.0243 \\
\hline
\end{tabular}


Table 15. Experimental and Analytical Results for Natural Frequencies of Coupled Modes in Viscous Fluids

\begin{tabular}{|c|c|c|c|c|c|}
\hline \multirow[t]{2}{*}{ Conditions } & \multirow{2}{*}{$\begin{array}{c}\text { Mode } \\
\text { Number }\end{array}$} & \multicolumn{2}{|c|}{$\begin{array}{l}\text { Measured Coupled } \\
\text { Natural Frequency, } \mathrm{Hz}\end{array}$} & \multicolumn{2}{|c|}{$\begin{array}{l}\text { Calculated Coupled } \\
\text { Natural Frequency, } \mathrm{Hz}\end{array}$} \\
\hline & & Water & Mineral 011 & Water & Mineral 0il \\
\hline \multirow{8}{*}{$\begin{array}{l}\text { In } \\
\text { unconfined } \\
\text { fluid }\end{array}$} & 1 & 56.79 & 56.93 & 57.90 & 58.82 \\
\hline & 2 & 62.79 & 62.65 & 62.99 & 63.76 \\
\hline & 3 & 66.26 & 63.28 & 66.73 & 67.47 \\
\hline & 4 & 67.38 & 67.58 & 67.87 & 68.62 \\
\hline & 5 & 69.53 & 69.75 & 69.66 & 70.23 \\
\hline & 6 & 71.88 & 74.22 & 71.38 & 72.01 \\
\hline & 7 & 74.32 & 76.57 & 74.19 & 74.70 \\
\hline & 8 & 76.95 & 77.08 & 76.39 & 76.78 \\
\hline \multirow{8}{*}{$\begin{array}{l}\text { Near a } \\
\text { flat wa11 } \\
\left(G_{w} / R=0.5\right)\end{array}$} & 1 & 56.25 & 57.09 & 57.17 & 58.12 \\
\hline & 2 & 60.11 & 61.15 & 60.52 & 61.44 \\
\hline & 3 & 64.36 & 63.00 & 64.08 & 64.80 \\
\hline & 4 & 66.70 & 66.31 & 66.11 & 66.92 \\
\hline & 5 & 68.51 & 68.65 & 68.30 & 68.99 \\
\hline & 6 & 70.68 & 70.13 & 69.60 & 70.26 \\
\hline & 7 & 72.99 & 72.7 .9 & 72.82 & 73.36 \\
\hline & 8 & 76.51 & 76.52 & 76.13 & 76.53 \\
\hline
\end{tabular}

